Programa de Mestrado Profissional em Hemoterapia e Biotecnologia Faculdade de Medicina de Ribeirão Preto - Universidade de São Paulo (USP)

Thaiana Cirqueira Gonçalves

\title{
Análise comparativa das metodologias de contagem manual e automatizada de plaquetas em plaquetopenias
}

Ribeirão Preto 


\section{THAIANA CIRQUEIRA GONÇALVES}

\section{Versão Original}

Análise comparativa das metodologias de contagem manual e automatizada de plaquetas em plaquetopenias

Dissertação apresentada à Faculdade de Medicina de Ribeirão Preto da Universidade de São Paulo para a obtenção do título de Mestre em Ciências.

Área de concentração: Hemoterapia e Medicina Transfusional.

Orientadora: Doutora Lorena Lobo de FigueiredoPontes

\section{Ribeirão Preto}


Autorizo a reprodução e divulgação total ou parcial deste trabalho, por qualquer meio convencional ou eletrônico, para fins de estudo e pesquisa, desde que citada a fonte.

\section{Catalogação da publicação}

\section{Serviço de Biblioteca e Documentação}

Hemocentro de Ribeirão Preto - Universidade de São Paulo

\section{Gonçalves, Thaiana Cirqueira}

Análise Comparativa das Metodologias de Contagem Manual e Automatizada de Plaquetas em Plaquetopenias/ Thaiana Cirqueira Gonçalves; Orientadora ProfaDra Lorena Lobo de FigueiredoPontes. - 2019

Dissertação de Programa de Mestrado Profissional em Hemoterapia e Biotecnologia apresentada à Faculdade de Medicina de Ribeirão Preto, Universidade de São Paulo. São Paulo, 2019

1. Plaquetopenia. 2. Contagem Manual de Plaquetas. 3. Pseudoplaquetopenia. 4. Segurança Transfusional. 
Nome: GONÇALVES, Thaiana Cirqueira

Título: Análise Comparativa das Metodologias de Contagem Manuel e Automatizada de Plaquetas em Plaquetopenias

Dissertação apresentada à Faculdade de Medicina de Ribeirão Preto da Universidade de São Paulo para a obtenção do título de Mestre em Ciências.

Aprovado em: / /

Banca examinadora

Prof. (a)Dr.(a):

Instituição:

Julgamento:

Prof. (a)Dr.(a):

Instituição:

Julgamento:

Prof. (a)Dr.(a):

Instituição:

Julgamento: 
Dedico este trabalho primeiramente à minha mãe que me ensinou que o estudo é o bem mais poderoso de um ser humano, e aos profissionais de saúde que através da sua vocação dedicam-se à vida do próximo. 


\section{AGRADECIMENTOS}

A Deus por todo o cuidado comigo, por ter me presenteado com mais essa conquista, pela força, sabedoria e auxílio na superação das dificuldades para a realização de mais esse sonho profissional.

À minha amada mãe, a quem me deu a vida, e quem é meu exemplo e minha força, a pessoa que se orgulharia imensamente deste momento e que estará contente olhando por mim e me guiando lá de cima.

Aos meus familiares e amigos, pela compreensão e paciência nos momentos de ausência e pelo encorajamento constante, apoio, amor e confiança.

À minha orientadora Dra. Lorena pelas contribuições no aprimoramento da minha formação profissionalcompartilhando seu vasto conhecimento e contribuindo integralmente para a concretização deste projeto.

Agradecimento especial à amiga e parceira profissional Mayara Aoyama pela cumplicidade no estudo da Hemoterapia.

Enfim, agradeço a todos que participaram para o meu crescimento profissionale pessoal em diversos e inúmeros momentos da minha vida, e que ajudaram a construir este trabalho direta ou indiretamente.

Obrigada! 


\section{RESUMO}

Introdução: As plaquetas são fragmentos de células sanguíneas produzidas na medula óssea, os megacariócitos, células precursoras da linhagem mielóide. 0 principal papel das plaquetas no corpo humano é a formação de tampão hemostático como resposta à lesão vascular. A diminuição das plaquetas decorre de diferentes processos fisiopatológicos, podendo estar relacionada com falência medula óssea ou a destruição plaquetária periférica. $\mathrm{O}$ exame de escolha para identificação da plaquetopenia é o hemograma, geralmente por meio de analisadores hematológicos automatizados. Todavia, existem desvantagens no método de automação que não podem ser desconsideradas. Dentre elas, destacase o fato de não ser possível observar alterações que possam causar interferências nos resultados. A plaquetopeniageralmente leva a um desequilíbrio na fase inicial do sistema hemostático, podendo ocasionar quadros de hemorragia. Para se reverter este quadro, a terapia mais utilizada nestes pacientes é a transfusão de plaquetas. Entretanto as indicações do concentrado de plaquetas devem levar em consideração o uso racional dos hemocomponentes devido aos riscos inerentes ao ato transfusional e a difícil manutenção do estoque por causa do seu curto prazo de validade. Por este motivo a contagem de plaquetas para identificação de defeitos na hemostasia é essencial, sendo de suma importância obter resultados fidedignos.

Objetivos: Avaliar a eficácia do uso do método de contagem manual de plaquetas considerando a correlação com a contagem automatizada, observando as discrepâncias nos resultados obtidos e possíveis consequências terapêuticas em pacientes plaquetopênicos atendidos no Instituto Hospital de Base de Brasília. Método: Foram analisados 227 exames de pacientes com contagens plaquetárias abaixo de $100.000 / \mu \mathrm{L}$. As amostras foram submetidas simultaneamente a contagem manual e a contagem automatizada pelo aparelho CellDynRuby. Resultado: A análise estatística apontou concordância regular entre os dois métodos, evidenciando que existe uma variabilidade moderada quando se compara os dois métodos de contagem. Conclusão: A metodologia manual pode ser utilizada de forma complementar à contagem automatizada de plaquetas, sendo a análise morfológica fundamental nos casos de plaquetopenias, afim de identificar alterações que podem influenciar no resultado final e acrescentar informações úteis ao diagnóstico.

Palavras chave: plaquetopenia, contagem manual de plaquetas, pseudoplaquetopenia, concentrado de plaquetas, segurança transfusional. 


\section{ABSTRACT}

Introduction: Platelets are fragments of blood cells produced in the bone marrow, megakaryocytes, precursor cells of the myeloid lineage. The main role of platelets in the human body is the formation of hemostatic tampon in response to vascular injury. The decrease in platelets results from different pathophysiological processes, and may be related to bone marrow failure or peripheral platelet destruction. The exam for identification of thrombocytopenia is the hemogram, usually by means of automated haematological analyzers. However, there are disadvantages in the automation method that can not be disregarded. Among them, highlights the factthat it is not possible to observe changes that may cause interference in the results. Thrombocytopenia usually leads to an imbalance in the initial phase of the hemostatic system, which can lead to bleeding. To reverse this condition, the most commonly used therapy in these patients is platelet transfusion. However, platelet concentrate indications should take into account the rational use of blood components due to the risks inherent to the transfusion and the difficult maintenance of the stock because of its short shelf life. For this reason, platelet count for hemostasis defect identification is essential, and it is extremely important to obtain reliable results. Objectives: To evaluate the effectiveness of using the manual platelet counting method considering the correlation with the automated counting, noting the discrepancies in the results obtained and possible therapeutic consequences in patients with thrombocytopenia treated at the Instituto de Base de Brasilia. Method: 227 patients were analyzed with platelet counts below 100,000 / $\mu \mathrm{L}$. The samples were simultaneously submitted to manual counting and counting automated by the Cell Dyn Ruby apparatus. Results: The statistical analysis indicated a regular concordance between the two methods, showing that there is a moderate variability when comparing the two counting methods. Conclusion: The manual methodology can be used in a complementary way to the automated platelet count, and the morphological analysis is fundamental in cases of thrombocytopenia, in order to identify changes that may influence the final result and to add useful information to the diagnosis.

Key words:thrombocytopenia, manual platelet counts, pseudothrombocytopenia, platelet concentrate, transfusion safety. 


\section{LISTA DE FIGURAS}

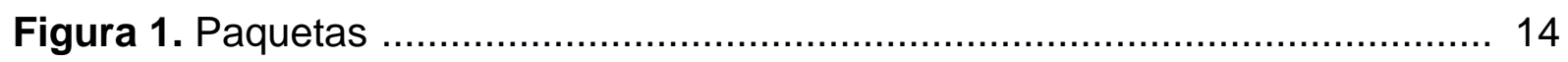

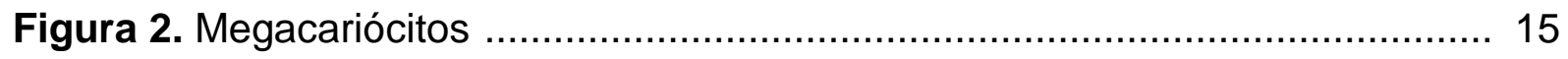

Figura 3. Hematopoese de células sanguíneas ................................................ 18

Figura 4. Causas de plaquetopenia/trombocitopenia .......................................... 21

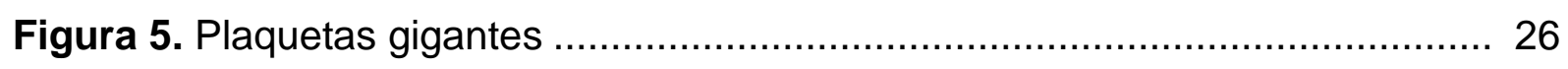

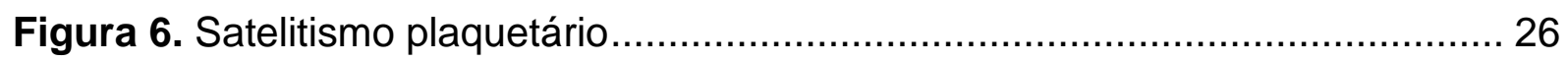

Figura 7. Agregação plaquetária ……………………............................... 27

Figura 8. Histograma de distribuição plaquetária ................................................. 29

Figura 9. Grade de contagem da Câmara de Neubauer .......................................... 31

Figura 10. Lamínula de quartzo e Câmara de Neubauer ......................................... 31

Figura 11. Diferença de densidade entre os componentes sanguíneos ................ 36

Figura 12. Centrifugação de bolsa de sangue total para obtenção de Plasma Rico

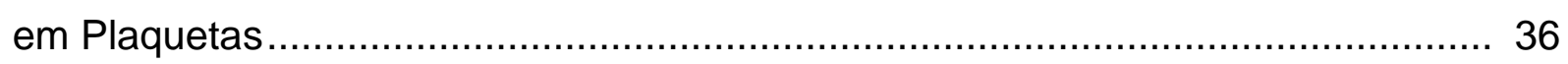

Figura 13. Centrifugação de Plasma Rico em Plaquetas para obtenção de Concentrado de Plaquetas ................................................................................... 37

Figura 14. Representação dos Hemocomponentes ............................................ 37

Figura 15. Área de Contagem de Plaquetas .................................................... 48

Figura 16. Preparo de esfregaço sanguíneo .................................................... 49

Figura 17. Distribuição dos exames analisados conforme sexo do paciente ........... 51

Figura 18. Distribuição dos exames analisados conforme diagnóstico.................... 53 


\section{LISTA DE TABELAS}

Tabela 1. Indicações Profiláticas de Transfusão de Concentrado de Plaquetas ...... 41

Tabela 2. Volumes para preparo da Solução de Contagem de Plaquetas ............... 47

Tabela 3. Distribuição dos exames analisados conforme causa da plaquetopenia.. 52

Tabela 4. Comparação estatística do método manual (CM) e automático (CA) de plaquetas dentre as causas de plaquetopenia.................................................. 54

Tabela 5. Comparação da média plaquetária pelo método manual $(\mathrm{CM})$ e automático (CA) conforme patologia dentro de cada grupo de causas de plaquetopenia 54 


\section{LISTA DE ABREVIAÇÕES}

ADP - Adenosina Difosfato

ATP - Adenosina Trifosfato

CCI - Coeficiente de Correlação Intraclasse

CIVD - Coagulação Intravascular Disseminada

CMV - Citomegalovírus

CP - Concentrado de Plaquetas

DNA - Ácido desoxirribonucleico

EDTA - Ácido etilenodiaminotetracético

FVW - Fator Von Willebrand

HCV- Vírus da Hepatite C

HPA - Antígeno Plaquetário Humano

IL - Interleucinas

LES - Lúpus Eritematoso Sistêmico

PRP-CP - Plasma Rico em Plaquetas

PTI - Trombocitopenia Imune Primária

PTT - Púrpura Trombocitopênica Trombótica

RNA - Ácido Ribonucleico

SHU - Síndrome Hemolítica-urêmica

SUS - Sistema Único de Saúde

TIH - Trombocitopenia induzida por heparina

UFC - Unidades Formadoras de Colônia

UFC-Li - Unidade Formadora de Colônia Linfocítica

UFC-Es - Unidade Formadora Esplênica

UFC-Meg - Unidades Formadoras de Colônia de Megacariócitos 


\section{SUMÁRIO}

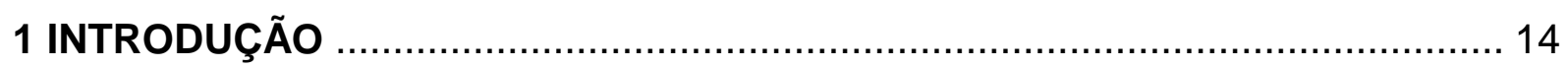

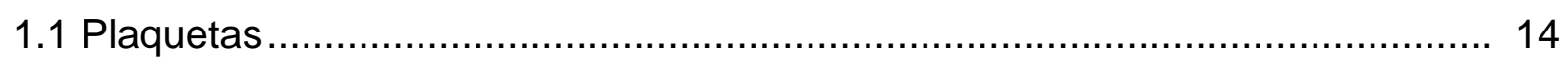

1.2 Hemostasia e Função Plaquetária ................................................................. 16

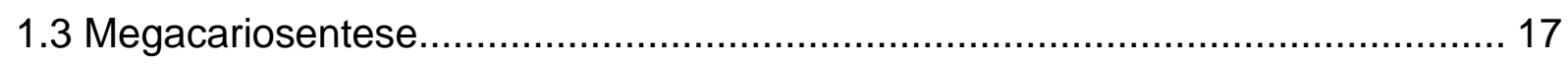

1.4 Trombopoetina

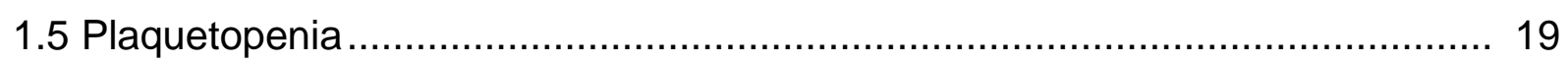

1.5.1. Diminuição da Produção de Plaquetas ..................................................... 22

1.5.2. Aumento da Destruição das Plaquetas .................................................... 23

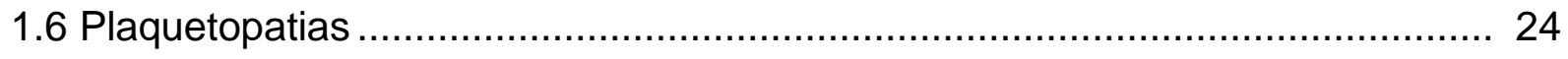

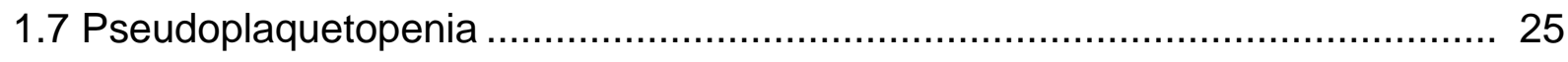

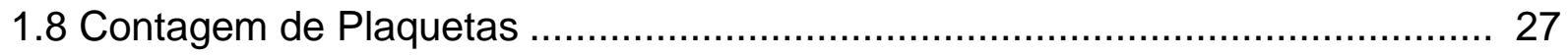

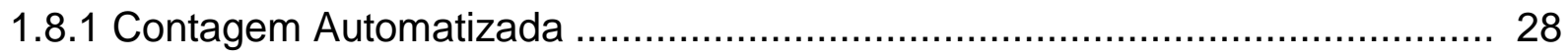

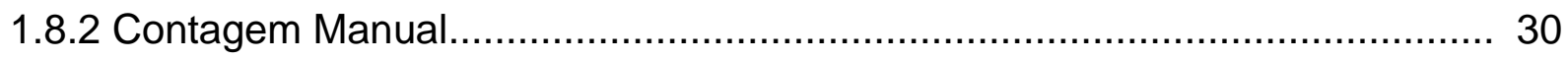

1.9 Interferentes das Contagem Plaquetária .................................................... 32

1.10 Transfusão de Concentrado de Plaquetas................................................. 34

1.10.1 Obtenção de Concentrado de Plaquetas .................................................. 35

1.10. 2 Indicação do Concentrado de Plaquetas .................................................. 39

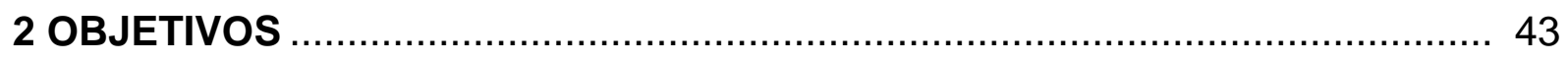

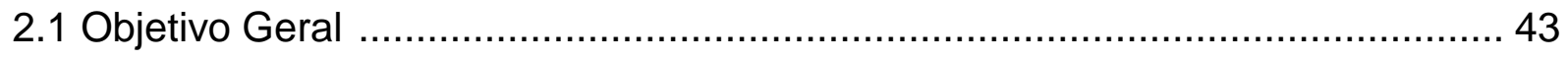

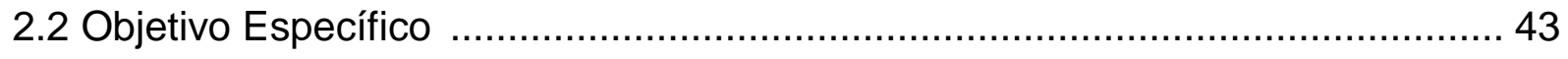

3 HIPÓTESE

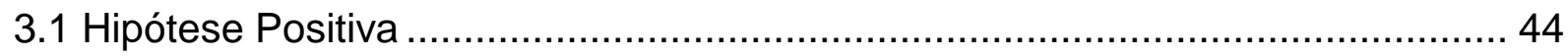

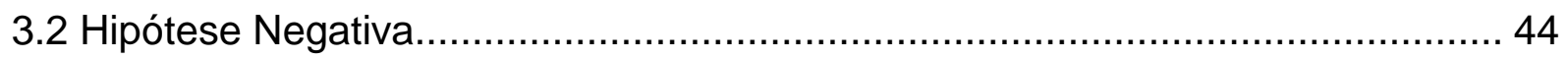

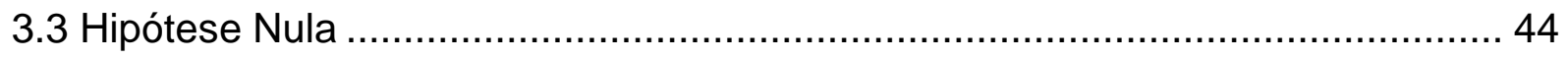

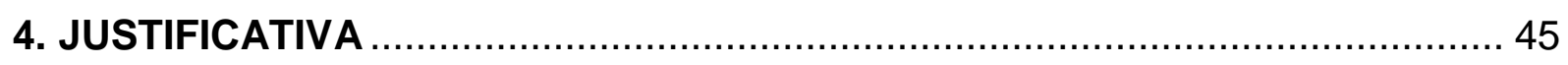




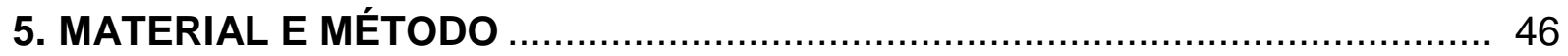

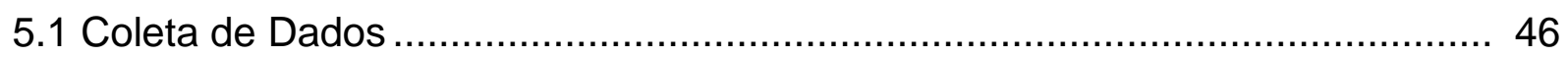

5.2 Metodologia da Contagem Automatizada de Plaquetas ................................. 46

5.3 Metodologia da Contagem Manual de Plaquetas ......................................... 47

5.4 Análise Morfológica das Plaquetas ......................................................... 48

5.5 Análise Estatística.......................................................................... 49

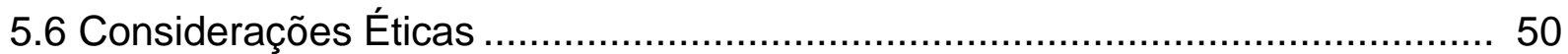

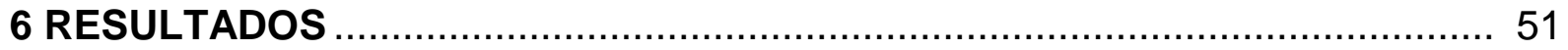

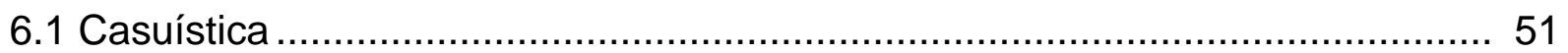

6.2 Comparação entre a Contagem de Plaquetas Manual e Automatizada ........... 52

6.3 Análise Morfológica das Plaquetas ............................................................. 55

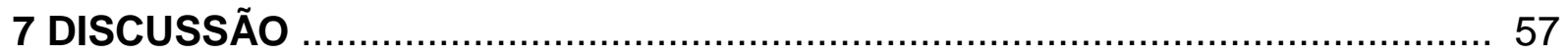

8 CONCLUSÃO

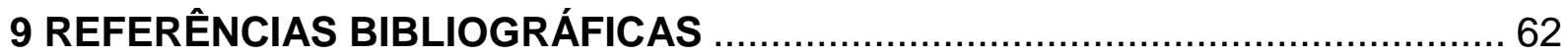




\section{INTRODUÇÃO}

\subsection{Plaquetas}

As plaquetas, também chamadas de trombócitos, são fragmentos de células sanguíneas produzidas na medula óssea. São anucleadas, ou seja, não possuem núcleo, medem em torno de 1,5 a 3 micrômetros de diâmetro, possuem volume plaquetar médio de 7-11fL, um formato discoide, e,um alto conteúdo energético (Figura 1) (PEERSCHKE, 2002).

Figura 1. Plaquetas. Microscopia de sangue periférico evidenciando plaquetas.

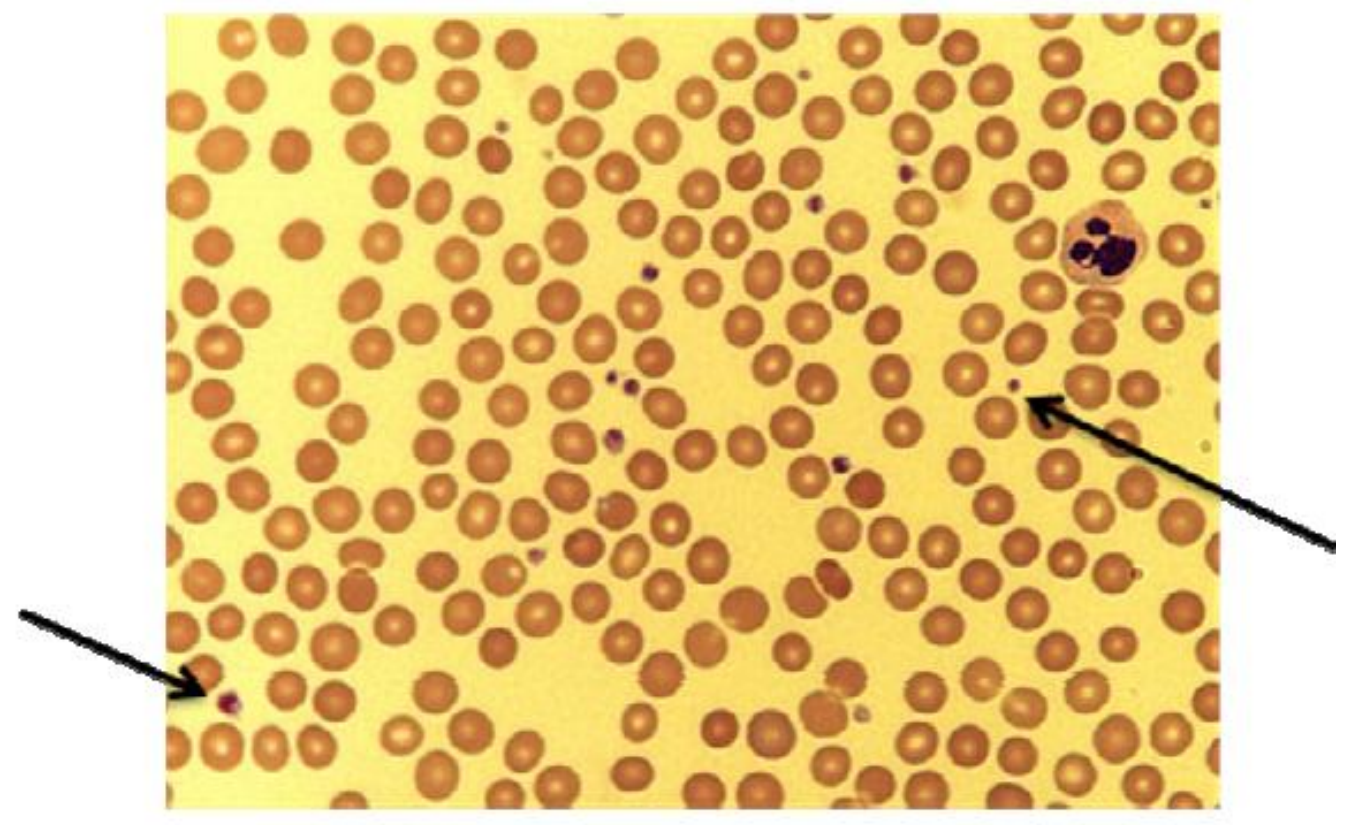

Fonte: FERREIRA, 2013.

As plaquetas contêm ácido ribonucleico (RNA), mitocôndria, um sistema canicular e vários tipos de grânulos - lisossomos contendo ácido hidrolico; corpos densos contendo adenosina difosfato (ADP), adenosina trifosfato (ATP), serotonina, histamina e cálcio; a grânulos contendo fibrinogênio, fator $V$, vitronectina, trombospondina e Fator Von Willebrand (FVW) (GRASSI \& ARAÚJO, 2012).

Por não apresentarem núcleo, a maioria das características morfológicas e biológicas das plaquetas são provenientes do material genético da sua célula precurssora, o megacariócito (HARTWIG \& ITALIANO, 2003). 
Os megacariócitos apresentam características morfológicas peculiares, destacam-se por possuírem um grande tamanho, em geral, medem de 10 a 15 vezes mais que os eritrócitos, sendo o seu diâmetro em média de 50-100 $\mu \mathrm{m}$. Durante a sua maturação, se expande e duplica seu ácido desoxirribonucleico (DNA) sem citocinese em um processo chamado endomitose, aumentando o tamanho do seu núcleo e o tornando multilobulado. O seu citoplasma, assim como o das plaquetas, contém a-grânulos e corpos densos(Figura 2) (WARRELL et al., 2005; THON \& ITALIANO, 2010).

Figura 2. Megacariócitos. Megacariocítos em aspirado de medula óssea.

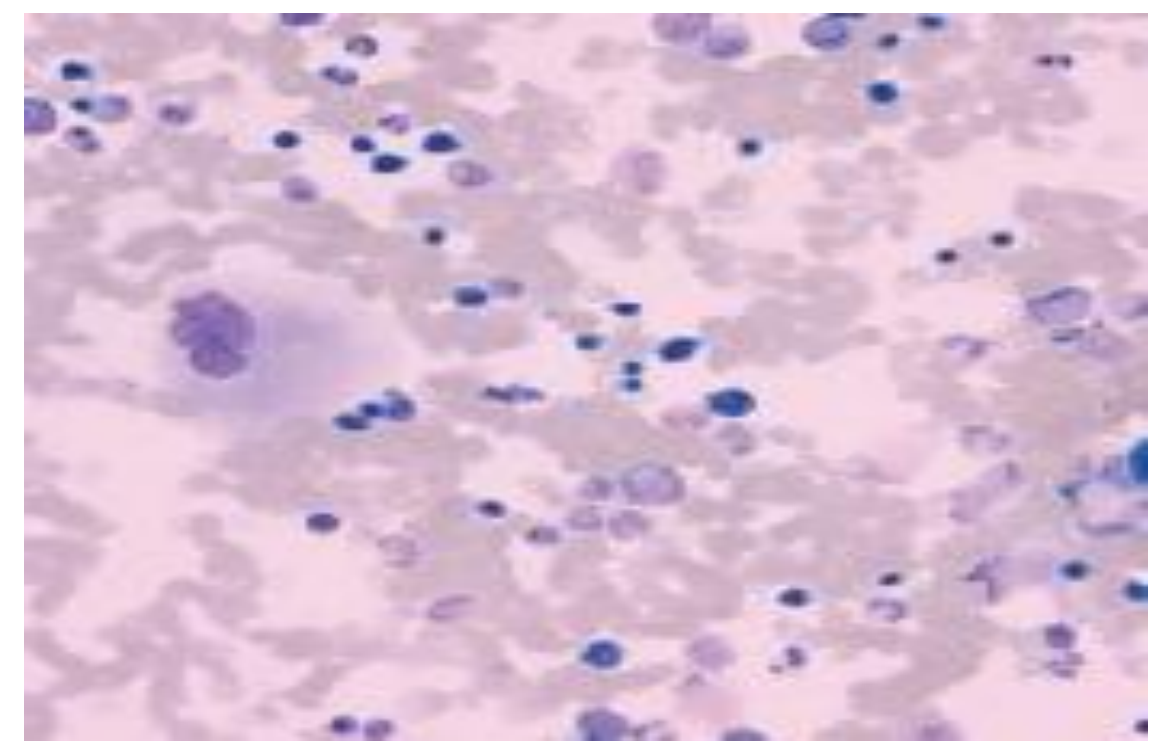

Fonte: SILVEIRA et al., 2011.

Um indivíduo considerado saudável possui em torno de 150.000 a $450.000 / \mu \mathrm{L}$ de plaquetas em sua circulação periférica. Considera-se que os indivíduos são plaquetopênicos quando os limites são inferiores a esses parâmetros e, acima do valor normal máximo, são considerados indivíduos com plaquetose (BRIGGS, HARRISON, MACHIN, 2007; HARRISON, 2007).

Diante do papel fundamental das plaquetas no sistema hemostático, exames que evidenciam os níveis plaquetários são indispensáveis para a avaliação de alterações na coagulação sanguínea (LEWIS et al., 2006). 


\subsection{Hemostasia e Função Plaquetária}

As plaquetas participam da hemostasia primária, especificamente da formação de tampão hemostático como resposta à lesão vascular (GREER et al., 2008).

A hemostasia em si tem o intuito de garantir a fluidez do sangue e a integridade dos vasos sanguíneos, ou seja, tem a função de manter o sangue dentro do vaso sanguíneo sem desencadear um processo de coagulação, prevenir processos hemorrágicos espontâneos e conter sangramentos traumáticos (JURK \& KEHREL, 2005).

A hemostasia pode ser realizada através de vários mecanismos: espasmo vascular, formação de tampão plaquetário, formação de coágulo sanguíneoefibrinólise (TORTORA \& DERRICKSON, 2013).

De acordo com o modelo clássico, a hemostasia atua sequencialmente nestas três etapas: hemostasia primária, hemostasia secundária e fibrinólise. Em especial, a hemostasia primária consiste na etapa inicial, e possuem como componentes o endotélio vascular, plaquetas e o FVW, os quais têm a finalidade de promover o tampão inicial e a vasoconstrição (TORTORA \& DERRICKSON, 2013).

As células endoteliais quando íntegras possuem propriedades antitrombóticas que inibem a coagulação do sangue dentro da luz dos vasos sanguíneos, todavia, quando ocorre uma lesão, passam a liberar citocinas com propriedades trombóticas, favorecendo o processo de coagulação no local do ferimento (JURK \& KEHREL, 2005).

Já as plaquetas possuem propriedades de adesão, agregação, secreção do conteúdo de seus grânulos e uma atividade pró-coagulante quando ativadas. Essa ativação ocorre quando há exposição de colágeno da membrana basal e estroma fazendo com que as plaquetas se liguem à superfície da parede do endotélio vascular. A ligação ocorre entre o complexo GPIb-IX-V, que encontra-se na superfície das plaquetas e o colágeno que fica exposto quando ocorre lesão do endotélio (HARRISON, 2007; CASTRO et al., 2006).

Esta ligação é facilitada pelo FVW que tem papel de receptor para a adesão plaquetária ao subendotélio. Além disso, o FVW participa na resposta vasoconstritoraque auxilia na redução do fluxo sanguíneo para as áreas lesadas, fazendo com que haja uma menor perca de sangue (TONACO, et al., 2010; RODAK, FRITSMA, DOIG, 2007;HARRISON, 2007). 
O processo de interação plaqueta-plaqueta dá origem ao tampão plaquetário, o qual é essencial para a hemostasia por interromper o fluxo de sangue para fora do vaso, segundos após a lesão inicial (LOPES, BIONDO, SANTOS 2007; HARRISON, 2005; FERREIRA, 2013).

Qualquer alteração em uma dessas funções ou no número total de plaquetas pode prejudicar a hemostasia. Um pequeno excesso ou déficit pode desencadear processos trombóticos ou hemorrágicos, podendo inclusive ser fatal (JURK \& KEHREL, 2005).

\subsection{Megacariocentese}

A hematopoese é o processo de mecanismos responsável pela produção dos diferentes tipos de células sanguíneas. Cada célula sanguínea é originada a partir de uma célula progenitora, chamada de célula-tronco hematopoéticapluripotente (NAOUM \& NAOUM, 2010).

Essas células pluripotentes são estimuladas através de diversos fatores, como as citocinas e fatores de crescimentos, capazes de fazer com que as células pluripotentes originem duas populações diferentes, as células progenitoras multipotentes, sendo uma mielóide e outra linfoide (NAOUM \& NAOUM, 2010).

A partir de então, formam-se as unidades formadoras de colônia (UFC), uma unidade formadora esplênica (UFC-Es) e outra unidade formadora de colônia linfocítica (UFC-Li). As UFC-Es darão origem aos eritróctios, granulócitos, monócitos e megacariócitos e as UFC-Li originarão os linfócitos T e B (BORDIN, LANGHI JÚNIOR, COVAS, 2007).

Através de cada UFC será formada uma população de células tronco, desta vez unipotentes que dará origem a um único e específico tipo de célula sanguínea (Figura 3) (BORDIN, LANGHI JÚNIOR, COVAS, 2007). 
Figura 3. Hematopoese de Células Sanguíneas. Produção de células sanguíneas de sangue periférico a partir de céula tronco pluripotente.

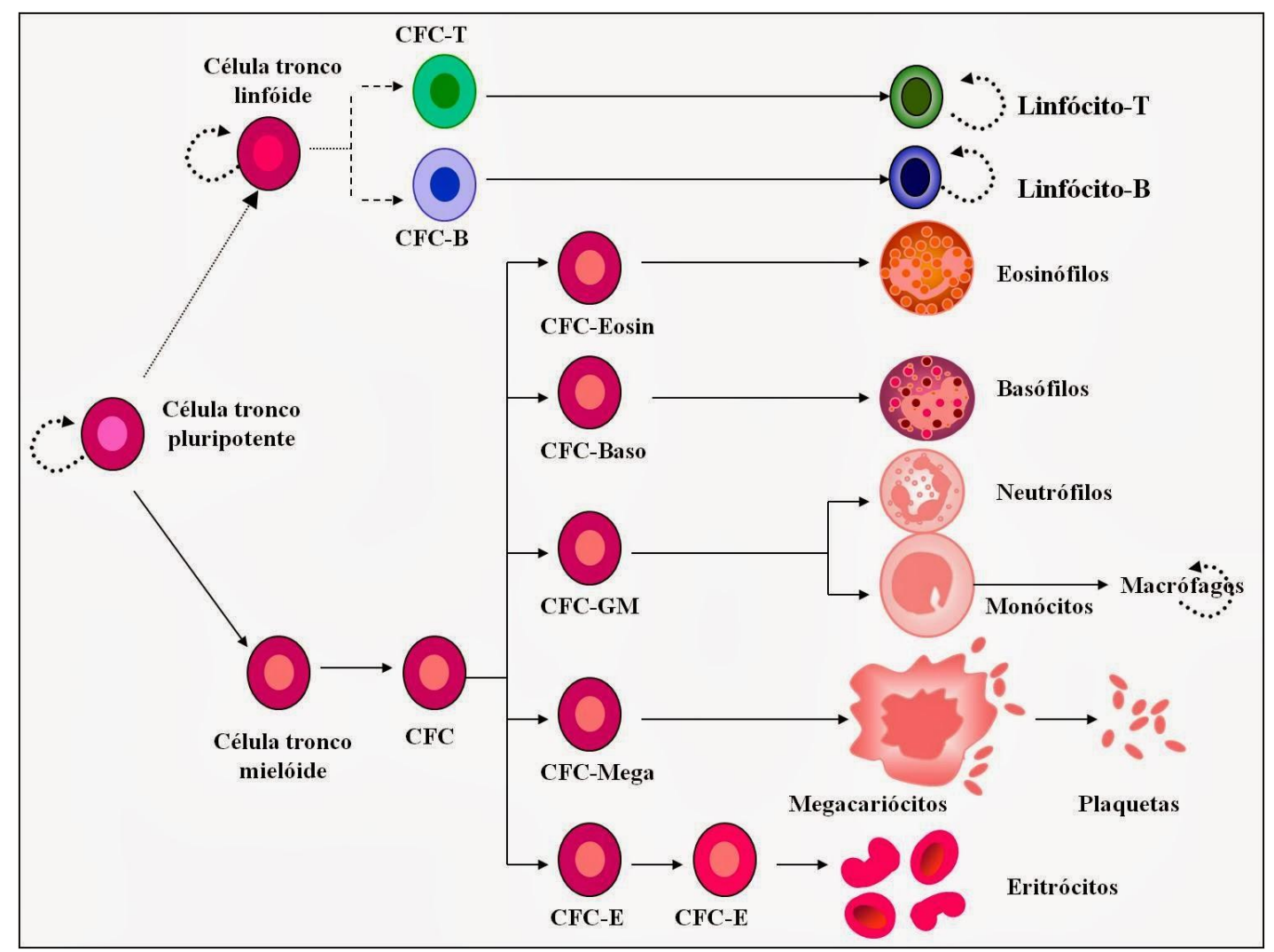

Fonte: BIOLOGIA AO COTIDIANO, 2013.

As unidades formadoras de colônia de megacariócitos (UFC-Meg), originadas das unidades formadoras mieloides, formam os megacariócitos. Estas células, mais especificamente seus fragmentos, darão origem às plaquetas (BORDIN, LANGHI JÚNIOR, COVAS, 2007).

As UFC-Meg formam o megacarioblasto, este tem uma característica importante, se torna uma célula com uma grande quantidade de material genético. $O$ megacarioblasto então dará origem ao megacariócito, que por sua vez, exposto a trombopoetina estimulará a biogênese das membranas internas celulares, dandoorigem às plaquetas maduras. Cada megacariócitoé capaz de originar milhares de plaquetas (HARTWIG \& ITALIANO, 2003; SMITH, PATHANSALI, BATH, 1999).

Existem duas teorias sobre omecanismo de formação das plaquetas. A primeira teoria, propõe a fragmentação citoplasmática dos megacariócitos, originando as plaquetas. Quando o citoplasma da célula adquire um tamanho exarcebado, tendo como consequênciao acúmulo de proteínas, há uma grande produção das 
plaquetas, como resultado ocorre uma liberação de forma massiva dessas células (BOILARD, et al. 2010).

A outra vertente de formação é a teoria das pró-plaquetas. Ocorre a formação de projeções dos microtúbulos nos megacariócitos, parte da membrana plasmática é projetada formando um compartimento citoplasmático, quando de desprendem, dão origem a estruturas intermediárias entre os megacariócitos e as plaquetas maduras, chamadas pró-plaquetas (ITALIANO et al., 2007; HARRISON, 2007).

As plaquetas maduras circulam na corrente sanguínea durante 8 a 10 diasem média, após, são removidas por monócitos ou macrófagos do sistema reticuloendotelial, levadas ao baço e destruídas (BRIGGS, HARRISON, MACHIN 2007).

\subsection{Trombopoetina}

A trombopoetina é o principal fator de crescimento da linhagem megacariocítica. Tem como função estimular a célula tronco pluripotente e células progenitoras jovens, além disso, participa da maturação dos megacariócitos, estando intimamente ligada na produção de plaquetas, ou seja, este hormônio regula todas as fases de desenvolvimento do megacariócito, desde o estímulo da célula tronco pluripotente até a maturação citoplasmática (DEUTSCH \& TOMER, 2006; KAUSHANSKY, 2009).

Outros estimuladores também moduladam essa ação, como citocinas e fatores humorais, são um exemplo, as interleucinas (IL) 3, 6 e 11; fatores estimulantes de colônia de granulócitos e macrófagos e, ainda, a eritropoetina. Em contrapartida, há os fatores humorais inibidores, como a $\beta$-trombomodulina e o fator plaquetário IV, os quais são proteínas específicas liberadas pelos a-grânulos que também participam daregulação da produção plaquetária (HARRISON, 2007; KAPSORITAKIS et al., 2001).

\subsection{Plaquetopenia}

O termo plaquetopenia é utilizado quando as plaquetas estão diminuídas na circulação sanguínea de um indivíduo. Como as plaquetas também podem ser denomiadas de trombócitos este termo também tem como nomenclatura à palavra trombocitopenia (PEERSCHK, 2002). 
Essa condição causa distúrbios hemostáticos capazes de resultarem em quadros de hemorragia, tendo como sinais visíveis aspetéquias, equimoses, sufusões, sangramentos gastrointestinais e urinários (SADLER, 2006).

Contagens acima de 100.000/ $\mathrm{L}$, sem nenhuma alteração na funcionalidade das plaquetas, não manifestam hemorragias. No caso de contagens plaquetárias entre 50.000 a $100.000 / \mu \mathrm{L}$, sangramentos após traumas podem ocorrer, entretanto pacientes com contagens entre 20.000 a $50.000 / \mu \mathrm{L}$, após sofrerem um pequeno trauma já é possível observar quadros de hemorragia, todavia, sangramentos espontâneos são incomuns. A possibilidade de ocorrer sangramentos espontâneos é mais comum quando a contagem de plaquetas é menor que 20.000/ $\mathrm{L}$, e sangramentos ativos com grande perda de volume aparecem quando as plaquetas

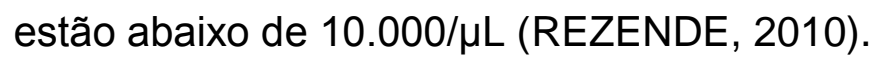

A plaquetopenia decorre de diferentes processos fisiopatológicos, estando relacionados à queda acentuada na produção pela medula óssea, ou um aumento do consumo de plaquetas, ou a destruição plaquetária periférica (Figura 4) (GUERRA et al., 2010). 
Figura 4. Causas de Plaquetopenia/Trombocitopenia. A plaquetopenia pode ser deconrrente da queda da produção de plaquetas pela medula óssea, pelo aumento de destribuição plaquetária que pode ocorrer devido a causas imunoogicas ou pelos trombos, ou ainda por outras causas como, por exemplo, transfusão maciça ou hiperesplenismo.

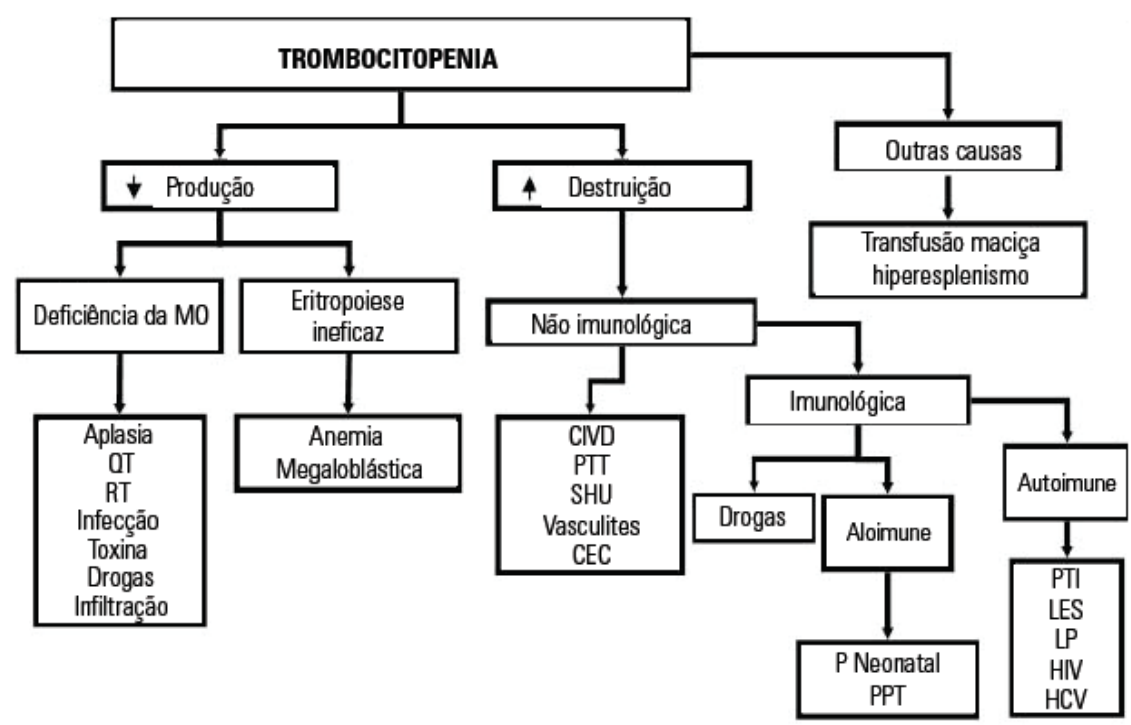

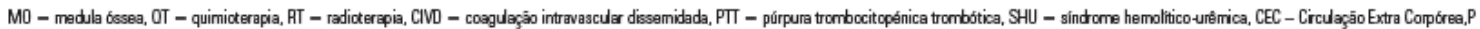

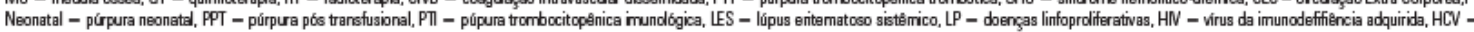
hepetite por vinus $\mathrm{C}$.

Fonte: GUERRA et al., 2011.

O aumento do número de megacariócitos pode indicar destruição ou aumento do consumo plaquetário, e a sua diminuição uma menor produção destas células (REZENDE, 2010).

A plaquetopenia por falência medular, ou seja, por diminuição da produção das plaquetas, deriva da insuficiência da produção de seu precursor, o megacariócito. Doenças da medula óssea, geralmente reduzem também a produção de outras células do sangue, acarretando em uma pancitopenia. Esse tipo de diminuição plaquetáriaestá vastamente relacionada com doenças hematológicas, oncológicas ou onco-hematológicas e ao tipo de tratamento utilizado nestas patologias, como a radioterapia e a quimioterapia. Para se reverter este quadro, a terapia mais utilizada na prevenção de hemorragias nestes pacientes é a transfusão de concentrado de plaquetas (BORDIN, LANGHI JÚNIOR, COVAS, 2007; SILVA \& NARDIN, 2012).

Outra causa de plaquetopenia está relacionado a fisiopatologia de destruição de plaquetas no sangue periférico por mecanismos autoimunes, como a produção de anticorpos antiplaquetários induzidos por algumas drogas, ou por doenças autoimunes como por exemplo o Lúpus Eritematoso Sistêmico (LES) ou 
Trombocitopenia Imune Primária (PTI). O consumo aumentado de plaquetas ocorre também por agregação das plaquetas a trombos (LOPES, 2009).

Outra causa de plaquetopenia pode ser derivada de diluição causada por transfusão maciça ou grande reposição de volume, sendo esta uma situação transitória. Há ainda pacientes com esplenomegalia que, consequentemente, retém as plaquetas no interior do baço, levando a uma diminuição dessas células na corrente sanguínea periférica (GUERRA et. al., 2011).

\subsubsection{Diminuição da Produção de Plaquetas}

Um dos mecanismos de plaquetopenia caracteriza-se pela diminuição da sua produção, seja derivado da falência medular, seja por deficiência na hematopoiese. Patologias que acometem a medula óssea como leucemias e síndromes mielodisplásicas são as principais causas de plaquetopenia neste grupo, normalmente são acompanhadas de outras citopenias (ADURA \& DOUGLAS, 2000).

A anemia aplásicatambém éum fator desencadeador da diminuição das plaquetas na circulação periférica, do mesmo modo tratamentos com quimioterápicos mielotóxicos ou radioterapia provocam a supressão medular. Tais condições não só podem causar a diminuição das plaquetas, como também de outras células sanguíneas. $O$ álcool igualmente é capaz de ocasionar mielosupressão, assim como infecções por microorganismos que evoluem com sepse (ADURA \& DOUGLAS, 2000).

As neoplasias geralmente cursam com plaquetopenia, isso porque, muitas vezes ocorre a infiltração da medula óssea prejudicando a hematopoiese das células (ANDRADE, 2009). As deficiências nutricionais, como a micronutrição de ferro, folato e vitamina B12, também podem dificultar a hematopoiese tonando a ineficaz, nestes casos a divisão celular é lenta e defeituosa, consequentemente levam a diminuição das células sanquíneas, inclusive as plaquetas. Cerca de $25 \%$ dos pacientes com diminuição de vitamina B12 no organismoapresentam quadros de plaquetopenia (COLARES-BENTO et al., 2009; PANIZ et al., 2005). 


\subsubsection{Aumento da Destruição Plaquetária}

Várias causas originam uma plaquetopenia por aumento de consumo, e podemos dividí-las em causas imunológicas e não imunológicas (GUERRA, et. al. 2011).

As microangiopatias são a maior ocorrência dentre as causas não imunológicas, a Púrpura Trombocitopênica Trombótica (PTT) e a Síndrome Hemolítica-urêmica (SHU) são um exemplo dessa classe, apatogênese plaquetária ocorre pela formação de trombos que retém as plaquetas, diminuindo a circulação dessas células. Microangioatias também podem ser induzidas por drogas (MOAKE, 2002).

A coagulação intravascular disseminada (CIVD) é uma síndrome adquirida descrita pela ativação descontrolada da coagulação intravascular, levando à formação e depósito de fibrina na microvasculatura, além das suas outras complicações como a alterações metabólicas e hemodinâmicas, oclusão vascular e comprometimento do fluxo sanguíneo, o consumo constante leva a depleção plaquetária e de fatores de coagulação, promovendo sangramentos ativos (PINTÃO \& FRANCO, 2001).

No âmbito das causas imunológicas, as plaquetopenias induzida por medicações são causas frequentes por sucitar anticorpos antiplaquetários. Dentre elas, podemos ressaltar a trombocitopenia induzida por heparina (TIH), a qual é uma complicação comum em pacientes que recebem terapia com heparina nãofracionada, que em sua forma mais grave está associada com risco de vida (ROBINSON \& LEWIS, 1999).

Síndromes autoimunes pré existentes podem predispor a ocorrência de anticorpos antiplaquetários como o LES e a PTI, sendo a PTI a causa mais comum de plaquetopenia grave em pacientes assintomáticos (WATERS, 1992). A destruição mediada por anticorpos pode levar a combinação de outras citopenias, quando isso ocorre, levando a também uma anemia hemolítica e PTI, classificamos como Síndrome de Evans (GUERREIRO, et al., 2002).

A púrpura imunomediada após a transfusão de concentrado de plaquetas(CP) é uma forma mais rara de destruição plaquetária, ocorre pela produção dealoanticorpos contra antígenos do sistema plaquetário humano (HPA) que se comportam como autoanticorposcausando a destruição das plaquetas (OLIVEIRA \&COZAC, 2003; BORDIN, LANGHI JÚNIOR, COVAS, 2007). 


\subsection{Plaquetopatias}

As plaquetopatias são derivadas de alterações hereditárias ou adquiridas da função plaquetária. Apresentam número de plaquetas normais, contudo possuem alterações funcionais e estruturais na ligação das plaquetas com o vaso sanguíneo, isto é, a adesão e a agregação plaquetária é deficitária na formação do tampão plaquetário, acarretando ineficiência na hemostasia primária podendo provocar sangramentos (REZENDE, 2010).

Dentre essas patologias podemos citar aquelas envolvendo defeitos nos receptores plaquetários, desordens granulares, deficiências de secreção, anormalidades em fatores plasmáticos, sendo capazes de gerar desordens e complicações clínicas aos pacientes (CASTRO et al, 2006).

A patologia mais comum dentre as que contêm defeitos nos receptores é a Síndrome de Bernard-Soulier, caracterizada pela presença de macroplaquetas e diminuição do quantitativo de plaquetas na circulação, causando um tempo de sangramento delongado. É uma doença autossômica recessiva, decorrente da ausência ou diminuição dos receptores para o FvW (Gplb-IX) (THOLOULI et al., 2004).

As desordens granulares configuram-se pela ausência de capacidadeplaquetáriaem estocar moléculas dentro dos grânulos, essas desordens podem ou não estar associadas adoenças sistêmicas (FLAUMENHAFT, 2003). Uma famosa patologia deste grupo é a Síndrome da Plaqueta Cinzenta, caracterizada por alterações morfológicas e bioquímicas nos a grânulos, presentetanto em plaquetas quanto emmegacariócitos. Os a grânulos são responsáveis por armazenar proteínas que promovem adesãoplaquetária, devido a sua diminuição ou ausência se tornam incapazes de reter-lás em seu interior. Morfologicamente as plaquetas se apresentam maiores e possuem uma cor acinzentada, sendo que a transfusão sanguínea está indicada em casos graves (ORANGE et al, 2004).

As deficiências de secreção são originadas a partir de defeitos na transdução de sinal de membrana, de vias metabólicas, nos mecanismos de secreção ou nas estruturas envolvidas diretamente na secreção do conteúdo granular após a ativação das plaquetas. Apresentam um tempo de sangramento prolongado e uma deficiência na liberação de ADP (FLAUMENHAFT, 2003; ORANGE et al., 2004) 
Anormalidades em fatores plasmáticos podem afetar o funcionamento das plaquetas, como a Doença de von Willebrand, que tem como patogenia a deficiência na produção do FvW, causando sangramentos, principalmentemucocutâneos. A afibrinogenemia,patologia que se observa níveis críticos de fibrinogênio, causa diminuição no número de plaquetas, comprometimento na interação plaquetaplaqueta e sintomas hemorrágicos que variam de leves a graves (NURDEN \& NURDEN, 2002).

Existem ainda as desordens que acarretam em um prejuízo na interação das plaquetas com os fatores de coagulação, nesta classe, podemos citar as doenças congênitas que envolvem macrotrombocitopenias, tais como as síndromes de MayHegglin, de Fechtner, de Sebastian e de Epstein, que ocorrem devido a uma mutação no gene MYH9 (BALDUINI, IOLASCON, SAVOIA 2002).

\subsection{Pseudoplaquetopenia}

Existe uma situação a qual se apresenta como uma falsa contagem baixa de plaquetas, chamada pseudoplaquetopenia, como o próprio nome sugere. Aproximadamente $15 \%$ (quinze por cento) das plaquetopeniassão caracterizadas comopseudoplaquetopenia ou plaquetopenia factícia (REZENDE, 2010).

Essa condição pode ser causada por vários fenômenos diferentes, tais como a presença de plaquetas gigantes (Figura 5) e agregadosplaquetários, os quais podem ser considerados como leucócitos nas contagens automatizadas e, consequentemente, ocasionar uma contagem de leucócitos erroneamente aumentada e uma pseudoplaquetopenia (MEINKOTH \& ALLISON, 2007; COMAR, DANCHURA, SILVA 2009). 
Figura 5. Plaquetas Gigantes. Presença de plaquetas gigantes próximo a hemácias em sangue periférico.

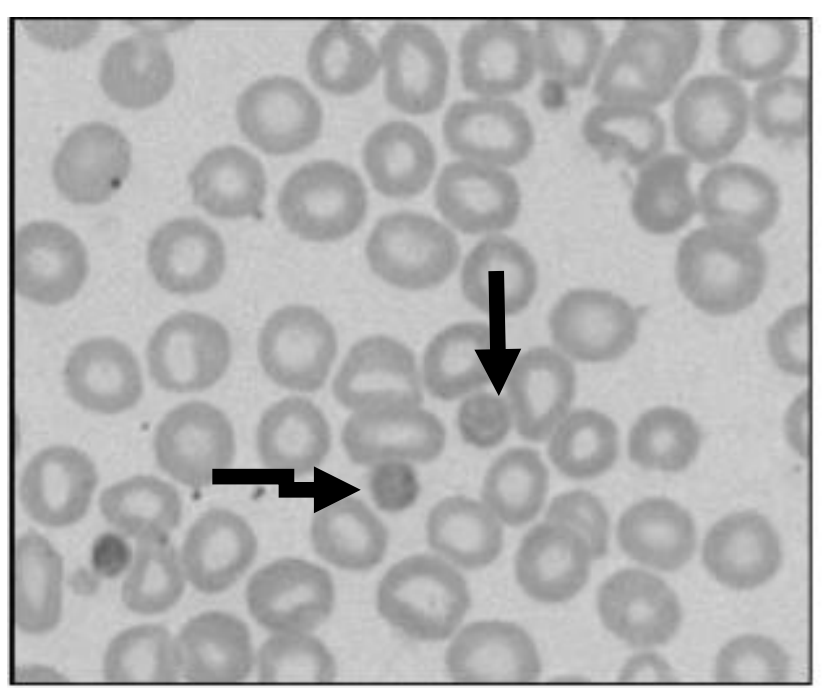

Fonte: FARIAS \& BÓ, 2010.

Outro fenômeno responsável pela diminuição da contagem do número de plaquetas é o satelitismo plaquetário (Figura 6), efeito que ocorre pela aderência das plaquetas aos leucócitos, muitas vezes, os aparelhos automatizados não conseguem realizar uma contagem condizente com essa realidade, provocando um exame equivocado. Podemos visualizar casos depseudoplaquetopenia em outras situações, como quando derivada de coleta inadequada com presença de coágulo e agregados plaquetários (Figura 7) ou ainda quando há presença de aglutininas frias (RIZZATTI \& FRANCO, 2001).

Figura 6. Satelitismo Plaquetário. Presença de plaquetas ao redor de neutrófilos formando o que chamou de rosetas.

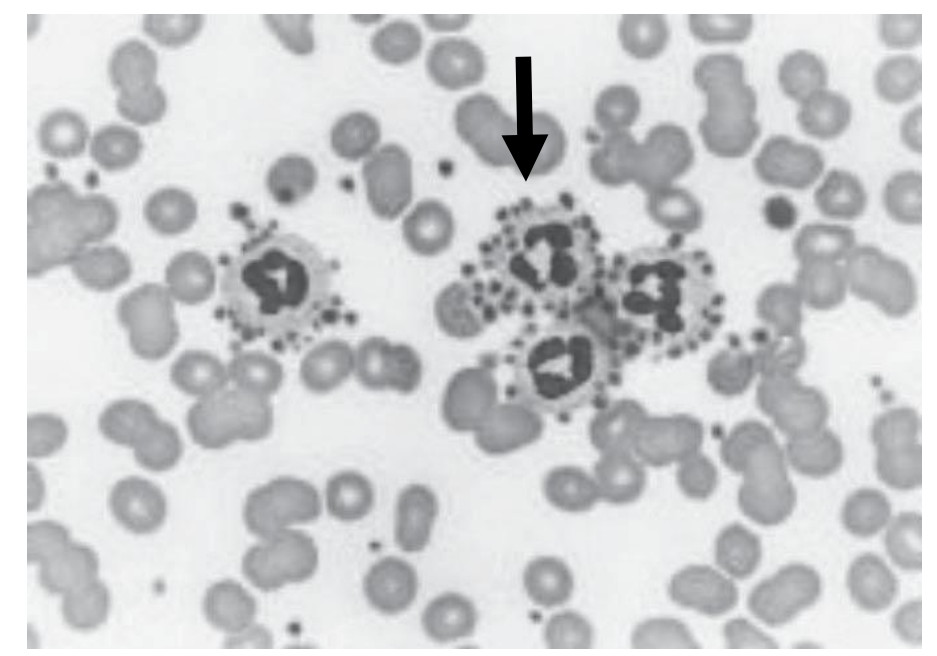

Fonte: DUSSE, VIEIRA, CARVALHO; 2004. 
Figura 7. Agregação plaquetária. Presença de grumo plaquetário próximo a um neutrófilo.

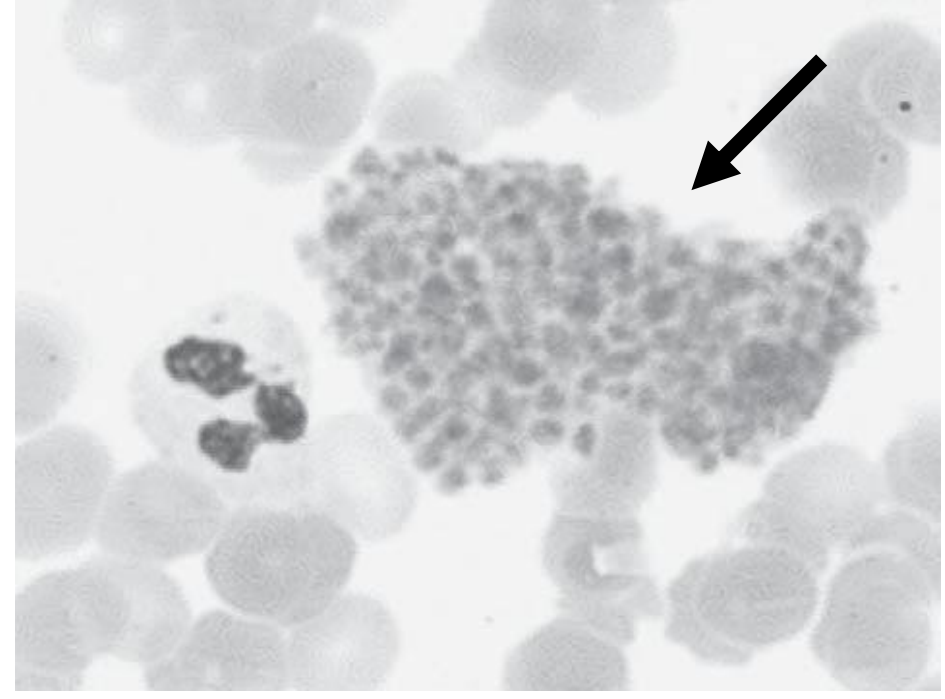

Fonte: DUSSE, VIEIRA, CARVALHO; 2004.

Acredita-se que a pseudoplaquetopenia ocorra com uma maior frequênciaem pacientes internados, estudos sugerem que este feito ocorra em cerca de $0,1 \%$ desses pacientes, principalmente aqueles com doenças hepáticas, auto-imunes e doenças neoplásicas. (RIZZATTI \& FRANCO, 2001; PAYNE \& PIERRE, 1984).

Esse quadro é considerado um problema clínico de relevância, pela possibilidade de acarretar em um diagnóstico equivocado, solicitações de exames laboratoriais e condutas terapêuticas desnecessária, incluindo a transfusão de plaquetas (DUSSE, VIEIRA, CARVALHO, 2004).

\subsection{Contagem de Plaquetas}

O exame de escolha para identificação de alterações plaquetáriasé o hemograma, sendo de suma importância resultados fidedignos.Atualmente, são utilizados contadores eletrônicos para realizar este procedimento, tal metodologia costuma ser bastante confiável, apresentando como vantagens o menor tempo de análise e maior reprodutibilidade, além de um ótimo custo benefício (MORENO \& MENKE, 2002). 
Todavia, existem desvantagens no método de automação, mesmo em analisadores de última geração, que não podem ser desconsideradas. Dentre elas destaca-se o fato de não ser possível observar alterações que possam causar interferências nos resultados, assim, agregados plaquetários, macroplaquetas e plaquetas gigantes podem levar a resultados falsamente diminuídos na contagem automatizada de plaquetas. (VAN DER MEER et al, 2003; MORENO \& MENKE, 2002).

Outro fator que deve ser levado em consideração é seu coeficiente de variação, o qual é menor que $10 \%$ em contagens entre 40.000 e 50.000/ $\mu \mathrm{L}$, porém, quando a contagem é menor que $20.000 / \mu$ Lo coeficiente de variação pode se elevar a aproximadamente $50 \%$, sendo este um fator indicativo de que podem ocorrer possíveis resultados não confiáveis (RIZZATTI \& FRANCO, 20012001 ).

\subsubsection{Contagem Automatizada}

Dentre os modelos de analisadores hematológicos comercializados no mercado há uma grande variação entre os métodos utilizados. No entanto, os princípios mais utilizados pela maioria dos analisadores são a impedância eletrônica e a análise ótica ou até mesmo a associação das duas técnicas (VIANNA, 2013).

A contagem por impedância elétrica baseia-se na análise dimensional, na qual as plaquetas são identificadas por seu tamanho. Todas as células passam uma a uma por um orifício aberto, inclusive as plaquetas, ao passar, as células alteram a corrente elétrica e então é emitido um sinal, um pulso elétrico, sendo o seu tamanho diretamente proporcional ao tamanho (volume) da célula, logo é possível distinguir o tipo específico de cada célula analisada.A quantidade de pulsos equivale ao número de células contadas neste sistema (FELLE et al., 2005).

O histograma plaquetário é a representação gráfica onde se visualizauma curva em que cada plaqueta é classificada e distribuída de acordo com seu tamanho (Figura 8) (FELLE et al., 2005). 
Figura 8. Histograma de distribuição plaquetária. Representação gráfica no exame de hemograma equivalente a distribuição de plaquetas confrome o seu tamanho.

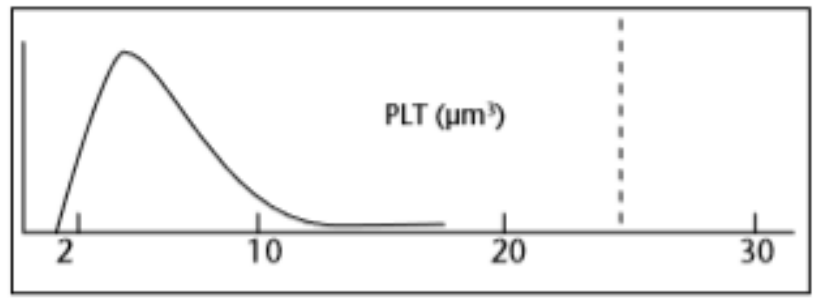

Fonte: FARIAS \& BÓ, 2010.

Já o método óptico, é uma técnica baseada pela medição simultânea de dois diferentes ângulos de dispersão de luz. A dispersão de luz de baixos ângulos sinalizada é amplificada 30 vezes, e a de altos ângulos 12 vezes. $O$ ângulo baixo é referente ao tamanho celular (volume) e o ângulo alto é referente ao índice de refração (densidade). Neste modelo de analisador, as plaquetas se apresentam com volumes de 0 a $30 \mathrm{fL}$, células com volume acima de $30 \mathrm{fL}$ são contadas na área dos eritrócitos (GIACOMINI et al., 2001).

A análise integrada é utilizada para diferenciar plaquetas, macroplaquetas, eritrócitos e células fragmentadas que tenham diferentes índices de refração (BRIGGS et al., 2000).

Uma nova tecnologia para contagem de plaquetas é a contagem por fluorescência ótica. O fuorocromo polimetina marca o conteúdo de RNA das células reticuladas, os grânulos e a membrana das plaquetas e produz fluorescência quando passam pelo laser. Essa metodologia realiza a contagem simultânea de eritrócitos, reticulócitos e plaquetas, pela diferença de intensidade do sinal de florescência de cada uma é possível distinguí-las. Além disso, esta metodologia consegue incluir na contagem plaquetária, de forma confiável, as macroplaquetas e plaquetas gigantes e consegue excluir partículas não plaquetárias (BRIGGS et al., 2000).

Os analisadores hematológicos podem realizar uma associação dessas metodologias, atualmente já exitem aparelhos realizando três contagens na mesma diluição: ótica, impedância e imunológica (ZANDECKI, et al., 2007).

A contagem de plaquetas por analisadores hematológicos automatizados nos proporciona a vantagem de um curto tempo de análise e uma altareprodutibilidade, além de um bom custo benefício (VELOSO, ALENCAR, CARDOZO, 2011).

Especificamente, o CellDyn Ruby nos fornece 22 parâmetros, em sua maioria feitos a laser por citometria de fluxo. A contagem de plaquetas é realizada por esse 
aparelho de forma diferenciada, através de dois ângulos óticos, os quais proporcionam uma maior precisão na contagem, assegurando resultados confiáveis logo na primeira corrida (LETHO, 2007).

\subsubsection{Contagem Manual}

A contagem manual de plaquetas pode ser recomendada com o propósito de adicionar informações úteis e confirmar as contagens fornecidas pelos analisadores hematológicos. Também é importante investigar mudanças morfológicas das células plaquetárias, isto é, presença de microplaquetas, macroplaquetas, plaquetas gigantes, anisocitoseplaquetose e grumos plaquetários (NOSANCHUK, CHANG, BENNETT, 1978; MORENO \& MENKE, 2002).

Para se obter contagem por microscopia, utilizando-se a Câmara de Neubauer, que consiste em uma lâmina grossa de vidro e mais alta que o normal, onde dentro se observa duas câmaras de contagem. A grade de contagem tem $3 \mathrm{~mm}$ x $3 \mathrm{~mm}$ de tamanho e é subdividida em 9 quadrantes de $1 \mathrm{~mm} \times 1 \mathrm{~mm}$, sendo a contagem realizada no quadrante central (Figura 9) (VIEIRA, 2000). 
Figura 9. Grade de Contagem da Câmara de Neubauer. Área referente ao local onde é realizado a contagem de plaquetas pelo método manual.

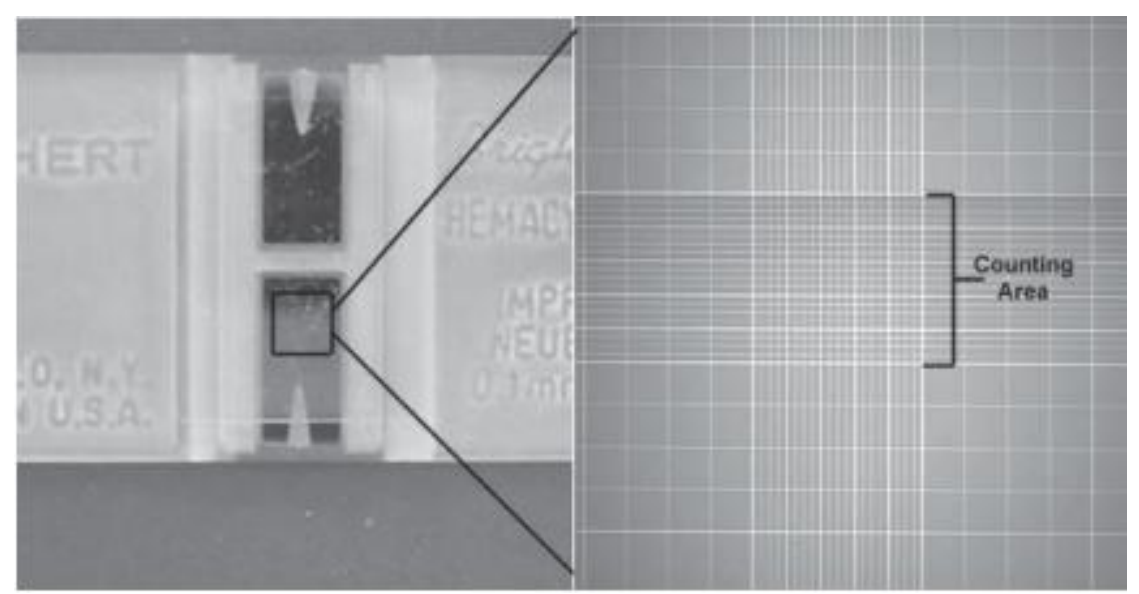

Fonte: ROUGE, 2002.

A amostra é colocada sobre a grade de contagem e em seguida coberta com uma lamínula específica de quartzo, para que seja possível realizar a contagem do quantitativo das células no miscroscópio (Figura 10) (LUCARINI, SILVA, BIANCHI 2004).

Figura 10. Lamínula de quartzo e Câmara de Neubauer. Vista lateralizada de Lamínula sobreposta em Câmara de Neubauer.

Vistalateral

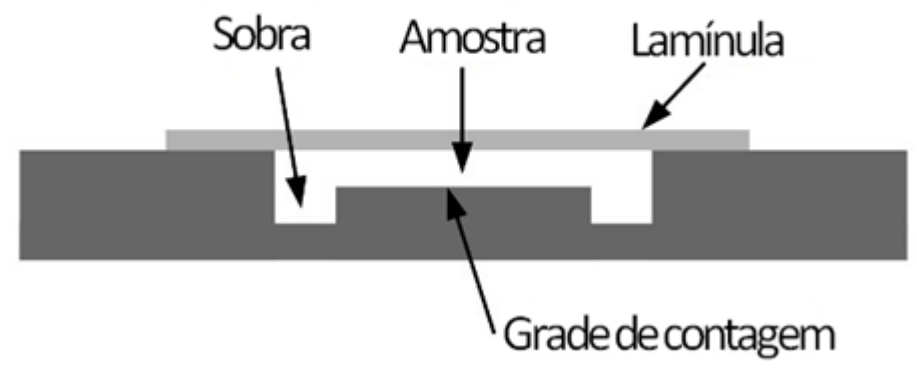

Fonte: CÂMARA, 2013.

Já a análise morfológica é feita em esfregaço sanguíneo com coloração geralmente de Giemsa ou Wright. Permite a visualização das caracteríscas das plaquetas analisadas, sendo item fundamental para determinar alterações, como plaquetas gigantes ou formações de grumos plaquetários (TASKER, CRIPPS, MACKIN, 2001; OLSEN et al., 2004). 
A metodologia de esfregaço sanguíneo possui como vantagem o seu baixo custo e agilidade, além de ser um suporte a calibração para os aparelhos automatizados. Porém, também apresentamdesvantagens, tais como, a necessidade de esfregaços sanguíneos padronizados, a baixa correlação entre o método padrão e a necessidade de esfregaços feitos imediatamente após a coleta (SILVA et al., 2007).

\subsection{Interferentes na Contagem Plaquetária}

Alguns fatores pré-analíticos e analíticos podem interferir no resultado final do exame de contagem de plaquetas, sendo as causas mais frequentes de erros neste diagnóstico a coagulação da amostra, agregação e o satelitismoplaquetário. Por issoé necessário uma padronização rigorosa para que se tenhamexames confiáveis (GREER et al, 2008).

$\mathrm{Na}$ fase pré-analítica, a coleta é um ponto crucial para exames plaquetários. O tempo de coleta prolongado ou a falta de homogeneização correta do tudo de sangue pode acarretar em coagulação parcial da amostra. Pacientes os quais apresentamuma coagulação da amostra podem se deparar com resultados falsamente diminuídos (COMAR, DANCHURA, SILVA, 2009).

O tempo também influencia na análise quantitativa e morfológica das plaquetas, uma vez que o sangue quando entra em contato como ácido etilenodiaminotetracético (EDTA), mesmo este sendo o anticoagulante de primeira escolha do exame de hemograma, algumas vezes pode ocasionar alteração na fisiologia normal das plaquetas. Amostras de sangue coletadas com esse anticoagulante podem alteram-se com o decorrer do tempo de exposição e com a temperatura tornando as plaquetas esféricas, entretanto, quando coletadas com citrato de sódio permanecem com seu formatodiscóide (DUSSE, VIEIRA, CARVALHO, 2004).

Sobre a falsa diminuição plaquetária pela exposição ao EDTA, seu macanismoainda é incerto, entretanto, existe uma teoria que acredita que autoanticorposcirculantes no plasma se ligam ao epítopo da glicoproteína Ilb localizado na superfície plaquetária, o qual somente é exposto quando entra em contato com o EDTA, esse fenômeno é capaz de promover a aglutinação das plaquetas (DUSSE, VIEIRA, CARVALHO, 2004). 
Outra alteração que podemos citar é a pseudossíndrome de plaquetas cinzentas, um fenômeno raro também dependente de EDTA, o qual consiste na desgranulação das plaquetas in vitro, gerando uma aparência cinza no sangue periférico. Tal ocorrência é conhecida como plaquetas fantasmaspor acarretar uma aparente diminuição da contagem plaquetária (LESESVE et al., 2005)

Uma opção para a interferência do EDTA é o uso de um anticoagulante alternativo ou ainda pela padronização entre o tempo da coleta e a análise da amostra. $\mathrm{O}$ citrato de sódio é o anticoagulante mais indicado para essa hipótese, previne a agregação plaquetáriaem pacientes com suspeita de pseudoplaquetopenia, promovendo contagem mais acurada (HARVEY, 2001).

Um fator que também pode ocasionar uma pseudoplaquetopenia é a formação de grumos plaquetários de tamanho próximo aos dos leucócitos como já foi abordado. Os analizadores hematológicos automatizados nessa situação podem levar a uma contagem equivocada, reconhecendo os grumos como leucócitos, consequentemente levando a umacontagem falsamente diminuída das plaquetas (MEINKOTH \& ALLISON, 2007; COMAR, DANCHURA, SILVA, 2009).

Assim como a coagulação parcial das amostras ou a formação de grumos plaquetários, as amostras com plaquetas gigantes também podem apresentar resultados falsamente diminuídos (COMAR, DANCHURA, SILVA, 2009).

Outro problema clínico pode ser ocasionado pelo satelitismo plaquetário, pois pode também acarretar em um diagnóstico errôneo, isso porque, algumas vezes as plaquetas colhidas em amostras de EDTA podem formar rosetas ao redor dos neutrófilos e novamente gerar um resultado de exame com contagens baixas não fidedigna com a realidade (RODAK, 2002).

Todavia, não só os interferentes pré-analíticos podem prejudicar a análise da contagem de plaquetas, a fase analítica também possui fatores com capacidade de prejudicar o resultado final do exame. Por exemplo, o principal parâmetro na metodologia de impedência é o tamanho do analito para diferenciar as plaquetas de outros analítos, porém todas as partículas com menos de $20 \mathrm{fL}$ podem ser contadas como plaquetas, como células fragmentadas, micrócitos, crioglobulinas ou qualquer outra causa que gere a formação de debris, reproduzindo uma contagem aumentada falsamente (KAITO et.al, 2005; KAKKAR, 2004).

Eritrócitos infectados por organismos também podem ser um problema nas análises, isso porque, bactérias podem gerar um pico plaquetário no histograma. Ocorre algo semelhante com a presença de fungos na corrente sanguínea, há 
relatos na literatura de pseudotrombocitopenia em pacientes infectados por Candida (YANG et al., 2006).

Outros estudos mostram que pacientes com hiperlipidemiaque possuem amostras coletadas após as refeições ou em nutrição parenteral, às vezes formam pequenas gotaslipêmicasin vitro, alterando a contagem de plaquetas quando contadas pela metodologia ótica, isso porque os lipídeos possuem alto índice refratário gerando sinais anormais próximos as plaquetas (YANG et al., 2006).

Além de interferentes analíticos nas contagens automatizadas, observam-se também nas contagens manuais. A montagem da câmara de Neubauer pode ser uma fonte de erro, caso ocorra variação na montagem, o volume da amostra pode ser alterado prejudicando o cálculo final da contagem das plaquetas (OLIVEIRA et al, 2003).

Outra fonte de erro é a diluição da amostra, pois seu preparo incorreto modifica a relação número de células por microlitro de sangue descredibilizandoa contagem das plaquetas. Deve se ter o mesmo raciocínio para a calibração das pipetas, o desajuste, assim como o não uso das ponteiras limpas pode comprometer o exame manual. Além disso, para tal metodologia, o analista deve possuir treinamento adequado e experiência, assim como utilizar de um bom microcópio para a análiseplaquetária (DANTAS, 2010; SILVA \& NADIN, 2012).

Observa-se que as duas metodologias possuem interferentes, os cuidados necessários, tanto na fase pré-analítica quanto analítica, devem ser adotados em todos os procedimentos a fim de minimizar a ocorrência de falsos resultados.

\subsection{Transfusão de Concentrados de Plaquetas}

O concentrado de plaquetas é vastamente utilizado na prática médica para tratamento de sangramentos em atividade ou preventivamente em pacientes plaquetopênicos, principalmente aqueles com histórico de doenças hematológicas malignas, oncológicas, sangramentos decorrentes de cirurgias ou traumas, e com uma menor freqüência em paciantes com disfunção plaquetária (DISTRITO FEDERAL, 2016; BORDIN, LANGHI JÚNIOR, D.M.; COVAS, 2007).

Quando a transfusão deste hemocomponente não era utilizada, cerca de $67 \%$ dos pacientes com quadro de hemorragia tinham o quadro agravado podendo 
chegar ao óbito. Após a implantação desta terapia, a incidência das hemorragias fatais diminuiram para aproximadamente $37 \%$ e, com a evolução do suporte transfusional terapêutico, este índice continua em declínio, proporcionando uma melhor expectativa de vida para pacientes com níveis críticos de plaquetas (BAYER et al, 1992).

A principal indicação clínica para a transfusão de plaquetas é o controle de sangramento secundário à plaquetopenia por falência medular, raramente são indicadas para reposição em casos de destruição periférica ou alterações congênitas de função plaquetária. A transfusão profilática de plaquetas pode ser indicada para pacientes com contagens plaquetárias inferiores a 10.000-20.000/ $\mu \mathrm{L}$ ou inferiores a 30.000-50.000/ $\mathrm{LL}$ antes de procedimento invasivo (HEIM et al, 2008; DISTRITO FEDERAL, 2016).

A indicação transfuisional requer avaliação individualizada do paciente apesar dos protocolos existentes, isso porque a transfusão de concentrado de plaquetas depende primeiramente da clínica que o paciente apresenta, podendo os valores utilizados como indicadores para transfusão variar em função das características de cada indivíduo, como idade, estado físico, comordidades associadas, resultado dos exameslaboratoriais eanálise do quadro clínico apresentado pelo paciente (DISTRITO FEDERAL, 2016).

\subsubsection{Obtenção de Concentrado de Plaquetas.}

Os hemocomponentes são oriundos da doação de sangue total, seu processamento é realizado através da técnica decentrifugo-sedimentação, ou seja, pela diferença de densidade dos componentes sanguíneos, podemos separá-los produzindo um componente específico para tratar de forma pontual a necessidade do paciente (Figura 11) (BRASIL, 1998). 
Figura 11. Diferença de densidade entre os componentes sanguíneos. Bolsa de sangue total após contrifugação. Visualiza-se os componentes conforme densidade, ao fundo da bolsa estão as células mais densas, as hemácias, logo acima o buffy-coat, sendo o sobrenadante formado pelo plasma.

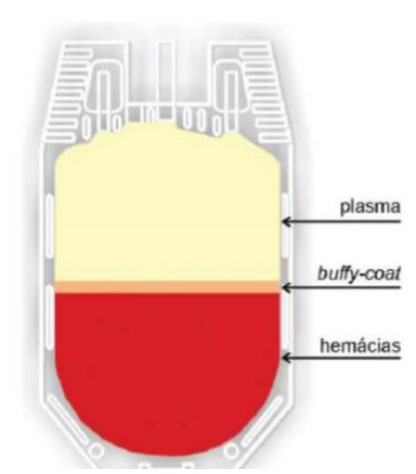

Fonte: Brasil, 1998.

O tempo de coleta da bolsa de sangue totalcom o intuito de produção de $\mathrm{CP}$, não poderá ser maior que 15 minutos, sendo preferencialmente coletada em até 12 minutos (BRASIL, 2016).

O fracionamento do sangue se inicia com a separação do plasma rico em plaquetas (PRP-CP) do sangue total por meio de uma leve centrifugação (Figura 12) (BRASIL, 2016).

Figura 12. Centrifugação de bolsa de sangue total para obtenção de Plasma Rico em Plaquetas. Após centrifugação leve da bolsa de sangue total, se obtém uma bolsa de concentrado de hemácias e outra bolsa de plasma rico em plaquetas.
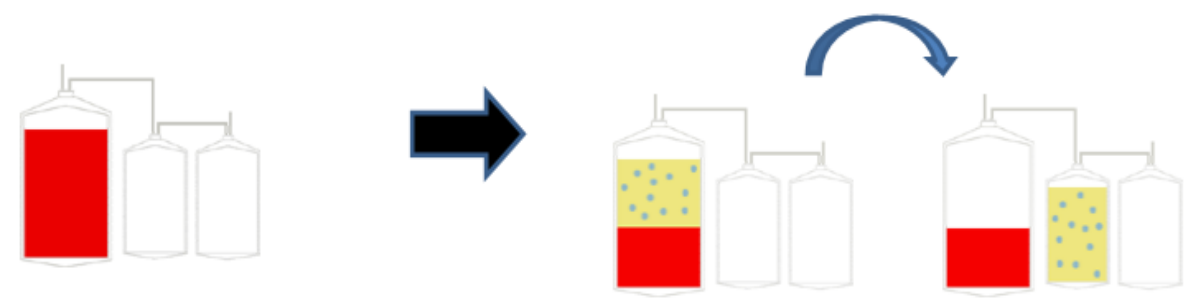

Fonte: Adaptado de Pinto, 2019.

Já o concentrado de plaquetas propriamente dito é obtido por meio da centrifugação pesada do PRP-CP (Figura 13) (BRASIL, 2016). 
Figura 13. Centrifugação de Plasma Rico em Plaquetas para obtenção de Concentrado de Plaquetas. Após centrifugação pesada de bolsa de plasma rico em plaquetas, se obtém uma bolsa de concentrado de plaquetas e outra de plasma.
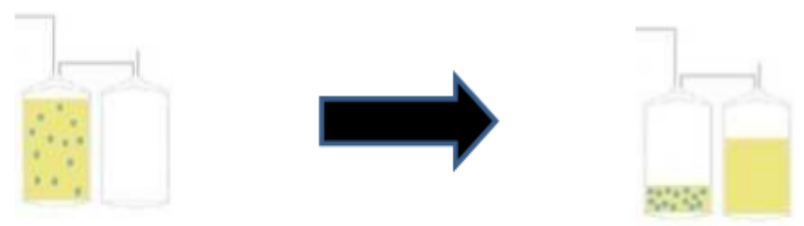

Fonte: Adaptado de Pinto, 2019.

As unidades de plaquetas provenientes de sangue total são chamadas de unidades randômicas (Figura 14). Cada unidade randômica contém aproximadamente $5,5 \times 10^{10}$ de plaquetas emergidas em aproximadamente 40 a 70 mLde plasma. $\mathrm{O}$ pH da bolsa deverá ser maior ou igual a 6,4 no último dia de validade do produto (BRASIL, 2016).

A armazenagem dos concentrados de plaquetas é feita emtemperatura ambiente $\left(22 \pm 2^{\circ} \mathrm{C}\right)$ sob leve agitação horizontal contínua (RAZOUK \& REICHE, 2004; BRASIL, 2016).

Figura 14. Representação dos Hemocomponentes. Representação das bolsas de sangue. Dupla que dá origem a dois hemocoponentes (geralmente, concentrado de hemácias e plasma); tripla (concentrado de hemácias, plasma e plaquetas randômicas ou crioprecipitado); e quádrupla (concentrado de hemácias, plasma e plaquetas randômicas e crioprecipitado).

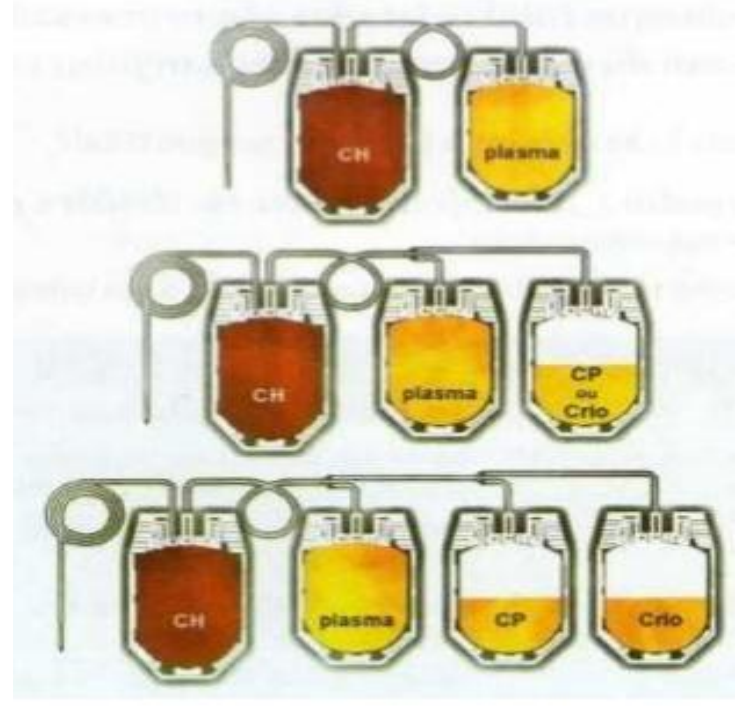

Fonte: Brasil, 1998. 
Já no sistema Top \& Bottom, o sangue total é coletado em bolsas triplas ou quádruplas. Essa metodologia consiste na centrifugação do sangue total fazendo com que se separem simultaneamente, o plasma fresco então fica alocado no topo (Top) e o concentrado de hemácias na base da bolsa primária, o qual é transferido para bolsa satélite com solução anticoagulante CPD-SAGM (HURTADO et al., 2000).

Assim, a camada leucoplaquetáriabuffy-coatsemantém na bolsa original de extração, após repouso de 01 a 12 horas sofre uma nova centrifugação, criando uma camada sobrenadante, a qual dará origem ao concentrado de plaquetas. Este por sua vez é transferido automaticamente para uma bolsa satélite, e o resíduo constituído de leucócitos, plasma e hemácias são desprezados. Este sistema permite uma acentuada redução dos leucócitos nos hemocomponentes, concentrados de hemácias e concentrado de plaquetas, que podem ainda receber nova leucorredução por filtros de bancada, filtros bed-side ou tecnologias com filtros in-line (HURTADO, et al., 2000).

Outro método de obtenção de plaquetas é o procedimento de aférese, em que as plaquetas são coletadas de um único doador, resultando em um hemocomponente com $3 \times 10^{11}$ de plaquetas, o qual equivale em média a seis unidades de plaquetas randômicas. Há a possibilidade de realizar coleta dupla, de dois hemocomponentes de aférese, para isso a contagem de plaquetas na bolsa deve ser superior ou igual a $6,0 \times 10^{11}$. Cada unidade de plaquetas por aférese deverá possuir volume maior ou igual que 200 mL (BORDIN, LANGHI JÚNIOR, COVAS, 2007;BRASIL, 2016).

Em 1975 iniciou-se a coleta de plaquetas por aférese de doadores únicos através de equipamento automatizado. No início, a coleta desse tipo de componente era realizada em casos específicos, como por exemplo, a fim de coleta de plaquetas HLA-compatíveis, HPA-1a negativas ou IgA deficientes. Em meados de 1980, as plaquetas por aférese começaram a fazer parte do estoque dos serviços de hemoterapia. Nos bancos de sangue dos Estados Unidos, dois terços do estoque de plaquetas é composto por aféreses e na Europa aproximadamente $50 \%$ do estoque é oriundo de plaquetaférese (HEAL\& BLUMBERG, 2004).

A coleta de plaquetas por aférese consiste em retirar através de separador celular automatizadoum determinado componente sanguíneo, no caso as plaquetas, recolhendo $o$ componente de interesse $e$ as outras células sanguíneas remanescentes são devolvidas ao doador. $O$ equipamento de coleta por aférese utiliza a metodologia de centrifugação e pela diferença de densidade das células 
consegue realizar a separação para a coleta específica. O rendimento plaquetário é definido para cada doador, dependendo das características de variáveis como peso, altura, contagem de plaquetas e nível do hematócrito do doador, as quais são fornecidas ao software da máquina, que por sua vez realiza oajuste automático de fluxo sanguíneo, fluxo do anticoagulante, relação anticoagulante/sangue total e tempo (VASSALO \& MURPHY, 2006).

As mesmas normas aplicadas aos doadores de sangue total devem ser aplicadas aos doadores de plaquetas por aférese, como por exemplo, realização de exames sorológicos para detecção de doenças transmitidas pelo sangue. $O$ intervalo entre duas plaquetaféreses em um doador é de 48 horas, podendo ser repetida no máximo 4 vezes por mês e 24 vezes por ano. O volume extra-corpóreo, ou seja, aquele retido na máquina, não deve ser superior a $15 \%$ da volemia do doador. 0 volume de sangue retido na câmara de separação ao final de cada procedimento deve ser monitorizado e registrado, se este volume atingir $9 \mathrm{ml} / \mathrm{kg}$ do doador a doação subseqüente deverá ocorrer após 2 meses para o doador masculino, e no caso de doador do sexo feminino, se este volume for superior a $8 \mathrm{ml} / \mathrm{kg}$, a doação poderá ser repetida em 3 meses. Um médico hemoterapeuta é responsável pelo procedimento, com monitorização clínica do doador, com garantia de disponibilidade de recursos para cuidados de emergência, em caso de reações adversas (BRASIL, 2016).

Apesar de ser um procedimento com um maior custo, esse tipo de coleta de plaquetas tem como vantagem a redução da exposição do paciente a vários doadores de sangue (VASSALO \& MURPHY, 2006).

\subsubsection{Indicação do Concentrado de Plaquetas}

As transfusões de concentrados de plaquetas geralmente estão indicadas emplaquetopenias desencadeadas por falência medular, como no caso de doenças hematológicas ou oncológicas. Também podem ser indicadas quando há existência de fatores de risco, como a realização de procedimentos invasivos, presença de sangramentos ativos e alterações da função plaquetária (DISTRITO FEDERAL, 2016). 
Os concentrados de plaquetas desleucocitados são provenientes da remoção de leucócitos por meio de filtros para este fim ou por meio de equipamento de aférese. Cada unidade de CP randômica deve conter um valor de leucócitos abaixo de 0,83 x $10^{6}$, já no caso do pool de CP desleucocitado obtido de sangue total e do concentrado por aférese, o valor dos leucócitos deve sermenor que 5,0 × $10^{6}$ (BRASIL, 2016).

Sua validade é de quatro horas, quando preparados em sistema aberto, se realizada a leucorredução em sistema fechado, os CP mantêm a validade original do produto. Os concentrados de plaquetas desleucocitados, assim como os concentrados por aférese que já são produzidos leucorreduzidos, são indicados a pacientes a fim de realizar aprofilaxia da aloimunização a antígenos leucocitários, e também são utilizados como prevenção para transmissão de Citomegalovírus (CMV) em substituição a componentes soronegativos para CMV (BRASIL, 2016)

Estudos apontam uma redução significativa da aloimunização e da refratariedadeplaquetária pelo uso de hemocomponentes filtrados, evidenciando a importância da leucorredução, assim, os CP leucorreduzidos estão indicados para todos os receptores, sempre que possível (MERYMAN, 1989).

Por sua vez, os CP irradiados são utilizados para reduzir o risco de Doença do Enxerto Contra o Hospedeiro, visto que esse processo permite a inativação dos linfócitos causadores dessa complicação. Estão destinados também a pacientes submetidos a transplante de medula óssea, quando há parentesco de primeiro grau do receptor com o doador, e, para transfusão de prematuros de peso inferior a 1.200 gramas. A dose de irradiação deve ser de 25 grays sobre o plano médio da unidade irradiada. Deve ser feita, preferencialmente, com irradiador de células próprio para irradiação de sangue ou hemocomponentes (BRASIL, 2016).

A transfusão profilática é responsável pela maioria das transfusões de concentrados de plaquetas. Estão elencados os casos mais comuns na tabela abaixo: 
Tabela 1. Indicações Profiláticas de Transfusão de Concentrado de Plaquetas. Indicações profiláticas de concentrado de plaquetas conforme Protocolo Transfusional da Secretaria de Estado de Saúde do Distrito Federal.

\begin{tabular}{|c|}
\hline Indicações Profiláticas de Transfusão de Concentrado de Plaquetas \\
\hline Quando paciente apresenta contagens inferiores a $10.000 / \mu \mathrm{L}$ na ausência de fatores de risco \\
\hline$\checkmark$ Se inferiores a $20.000 / \mu \mathrm{L}$ na presença de fatores associados a quadros de hemorragia \\
\hline $\begin{array}{l}\text { Em crianças, estudos científicos mostram que pacientes pediátricos toleram um nível } \\
\text { plaquetário menor, sendo assim, nestes a indicação se dá quando as contagens de plaquetas } \\
\text { estiverem menores que } 5.000 / \mu \mathrm{L} \text { (estáveis) }\end{array}$ \\
\hline
\end{tabular}

$\checkmark$ Pacientes adultos portadores de tumores sólidos: por terem um maior risco de sangramento devido ao tratamento, é indicado transfusão de plaquetas quando atingirem níveis inferiores a $20.000 / \mu \mathrm{L}$.

$\checkmark$ Pacientes adultos portadores de tumores sólidos: por terem um maior risco de sangramento devido ao tratamento, é indicado transfusão de plaquetas quando atingirem níveis inferiores a $20.000 / \mu \mathrm{L}$.

$\checkmark$ Pacientes portadores de anemia aplástica grave ou síndrome mielodisplásicapossuemindicação profilática quando as contagens estiverem inferiores a $5.000 / \mu \mathrm{L}$ ou se inferiores a $10.000 / \mu \mathrm{L}$, na presença de manifestações hemorrágicas.

$\checkmark$ Quando pacientes em procedimentos cirúrugicos com a utilização de circulação extracorpórea superior a 90-120 min, por comprometer a função plaquetária, nesses casos de possibilidade de desencadeamento de hemorragia intraoperatória está indicado transfusão mesmo com contagens superiores a 50.000/ $\mu \mathrm{L}$.

$\checkmark$ Transfusão maciça: quando contagem inferior a $50.000 / \mu \mathrm{L}$ se aproximadamente duas volemias sanguíneas forem trocadas do paciente, ou se inferior a $100.000 / \mu \mathrm{L}$ na presença de alterações graves da hemostasia, trauma múltiplo ou de sistema nervoso central. 
$\checkmark$ Cirurgias: A literatura contraindica transfusão em contagens superiores a $50.000 / \mu \mathrm{L}$, pois tal contagem é suficiente para a maioria dos casos, exceto para procedimentos neurocirúrgicos e oftalmológicos para os quais níveis mais elevados são exigidos (superiores a 80.000 a $100.000 / \mu \mathrm{L})$.

Fonte: Protocolo Transfusional- Indicação de Hemocomponentes - Secretaria de Estado de Saúde do Distrito Federal (2016).

O concentrado de plaquetas é um componente bastante utilizado nas rotinas transfusionais, entretanto, apesar da sua grande produção, seu aproveitamento é limitado, pelo fato de sua validade ter um curto prazo de tempo, de até cinco dias na dependência do tipo de plástico da bolsa, o que gera, muitas vezes, a indisponibilidade de uso deste hemocomponente. Outro ponto que deve se dar importância são os custos de produção, uma vez que os avanços tecnológicos dos métodos de obtenção do produto e melhoria de qualidade causam uma elevação no valor dohemocomponente. Logo, a obtenção de CP em quantidade e qualidade satisfatória ainda é um desafio para os serviços hemoterápicos, pois a disponibilidade para a demanda diária ainda é insuficiente (Cameron et al, 2007).

Assim, além de se ter em mente osriscos inerentes ao ato transfusional e exposição do paciente, deve-se levar em consideração, nos casos dos concentrados de plaquetas, a difícil manutenção do seu estoque, sendo necessário que as indicações sejam pautadas em protocolos com o intuito de racionalizar o uso com critérios que favoreçam o paciente e proporcionem o uso racional do sangue e hemocomponentes. 


\section{OBJETIVOS}

\subsection{Objetivo Geral}

Avaliar a eficácia do uso do método de contagem manual de plaquetas considerando a correlação com a contagem automatizada no equipamento CellDynRuby, observando as discrepâncias nos resultados obtidos em pacientes plaquetopênicos atendidos no Instituto Hospital de Base de Brasília.

\subsection{Objetivo Específico}

1) Comparar a metodologia automatizada e a metodologia manual de plaquetas em pacientes com quadro de plaquetopenia abaixo de 100.000/ $\mu \mathrm{L}$.

2) Correlacionar o resultado obtido da amostra do paciente com o diagnóstico hematológico, alterações morfológicas das plaquetas e ocorrência de transfusão. 


\section{HIPÓTESE}

3.1. Hipótese Positiva: verificar a eficácia da metodologia manual da contagem de plaquetas em casos de plaquetôpenias, afirmando a importância da utilização de forma complementar desta metodologia quando a contagem automatizada não for suficiente, assim, evidenciando uma discrepância devido a fatores morfológicos ou fisiológicos das plaquetas ou ainda por um déficit na metodologia automatizada tendo como conseqüênciaresultadosdivergentes do número de plaquetas.

3.2. Hipótese Negativa: evidenciar que a metodologia manual é ultrapassada, sendo seu uso inadequado e que a utilização de metodologia automatiza por si só é suficiente no diagnóstico de plaquetopenias em qualquer situação clínica.

3.3. Hipótese Nula: não identificar relevância na utilização das duas metodologias concomitantemente. 


\section{JUSTIFICATIVA}

Considerando a relevância da contagem precisa do número de plaquetas em situações de doenças plaquetárias, este trabalho tem o intuito de se aprofundar no tema e gerar informações relevantes para o diagnóstico de plaquetopenias. Embora a técnica de contagem manual de plaquetas tenha caído em desuso, essa ferramenta, se aplicada de forma coerente, pode contribuir para a investigação da causa bem como confirmação das contagens em indivíduos plaquetopênicos.

$\mathrm{O}$ uso da metologia da contagem manual de plaquetas de forma complementar pode, em alguns casos, evidenciar uma discrepância no resultado obtido, visto que nestes determinados casos a contagem automatizada pode não ser suficiente. Os dados obtidos poderão contribuir para que ocorra uma melhoria no atendimento aos pacientes com plaquetopenia e para a racionalização no uso de concentrados de plaquetas. 


\section{MATERIAL E MÉTODO}

O estudo foi realizado no Instituto Hospital de Base de Brasília, especificamente na agência transfusional do hospital, que por sua vez é assistida pela Fundação Hemocentro de Brasília, que disponibiliza todos os hemocomponentes para atendimento, assim como todo o processamento das bolsas de sangue e quando necessário, testes complementares de imuno-hematologia.

A agência transfusional do Instituto Hospital de Base realiza os seus próprios exames de hemograma em setor interno - laboratório de hematologia especializado a realizar exames de pacientes atendidos pela Hemoterapia. Todos os pacientes são provenientes do Sistema Único de Saúde (SUS).

\subsection{Coleta de Dados}

Realizada análise retrospectiva, onde foram incluídos os pacientes plaquetopênicos, com contagens abaixo de 100.000/ $\mu \mathrm{L}$, atendidos pelo Banco de Sangue do Instituto Hospital de Base de Brasília durante o período de maio 2018 a dezembro de 2019, que realizaram contagem automatizada e manual de plaquetas.

Os dados foram coletados dos arquivos eletrônicos do Banco de Sangue tais como resultados de hemograma, doença de base, idade, sexo e a ocorrência de transfusão.

\subsection{Metodologia da Contagem Automatizada de Plaquetas}

Os exames de hemograma automatizados foram realizados no próprio banco de sangue no setor de hematologia com o analisador hematológico automatizado de múltiplos parâmetros, CellDyn Ruby - Abbott. Esse equipamento utiliza a metodologia de MAPSS (Dispersão Polarizada Multiangular) oferecendo leituras ópticas, sendo os leucócitos diferenciados em 4 ângulos, a série vermelha em 3 ângulos e a série plaquetária em 2 ângulos. 


\subsection{Metodologia da Contagem Manual de Plaquetas}

As amostras foram submetidas simultaneamente a contagem manual de plaquetas em Câmara de Neubauer.

Primeiramente, a amostra de sangue foi sedimentada espontanemante, a fim de se obter plasma rico em plaquetas. Logo após essa etapa, em um tubo de ensaio, adicionou-se $20 \mu \mathrm{L}$ de plasma rico em plaquetas e $1 \mathrm{~mL}$ de líquido diluidor, formol salina $1 \%$ (Tabela 2 ).

Tabela 2. Volumes para preparo da Solução de Contagem de Plaquetas. Para preparo de solução de contagem de plaquetas pela metodologia manual, deve-se, em um tubo de ensaio, adicionar $20 \mu \mathrm{l}$ do plasma rico em plaquetas da amostra de sangue do paciente em análise e $1 \mathrm{ml}$ de formol salina $1 \%$.

\begin{tabular}{lc}
\hline & Volume \\
Amostra do paciente & $20 \mu \mathrm{L}$ \\
Formol Salina 1\% & $1 \mathrm{Ml}$ \\
\hline
\end{tabular}

Com o auxílio de uma pipeta preencheu-se o retículo da Câmara de Neubauer, evitando excesso de líquido e bolhas de ar. Por cima da Câmara posicionou-se a lâmina de quartzo, e deixou-se incubar em placa de petri com gaze umedecida por 10 minutos a fim de sedimentar as plaquetas.

Posteriormente, a contagem manual de plaquetas foi realizada análise microscópica utilizando-se a objetiva de 200X. Foram contadas todas as plaquetas encontradas no quadrante da região central, em razão das amostras sabidamente possuírem contagem inferior a 100.000/ $\mathrm{LL}$ (Figura 15). 
Figura 15. Área de Contagem de Plaquetas. Quadrante da região central da Câmara de Neubauer onde, neste estudo, foram contadas todas as plaquetas encontradas.

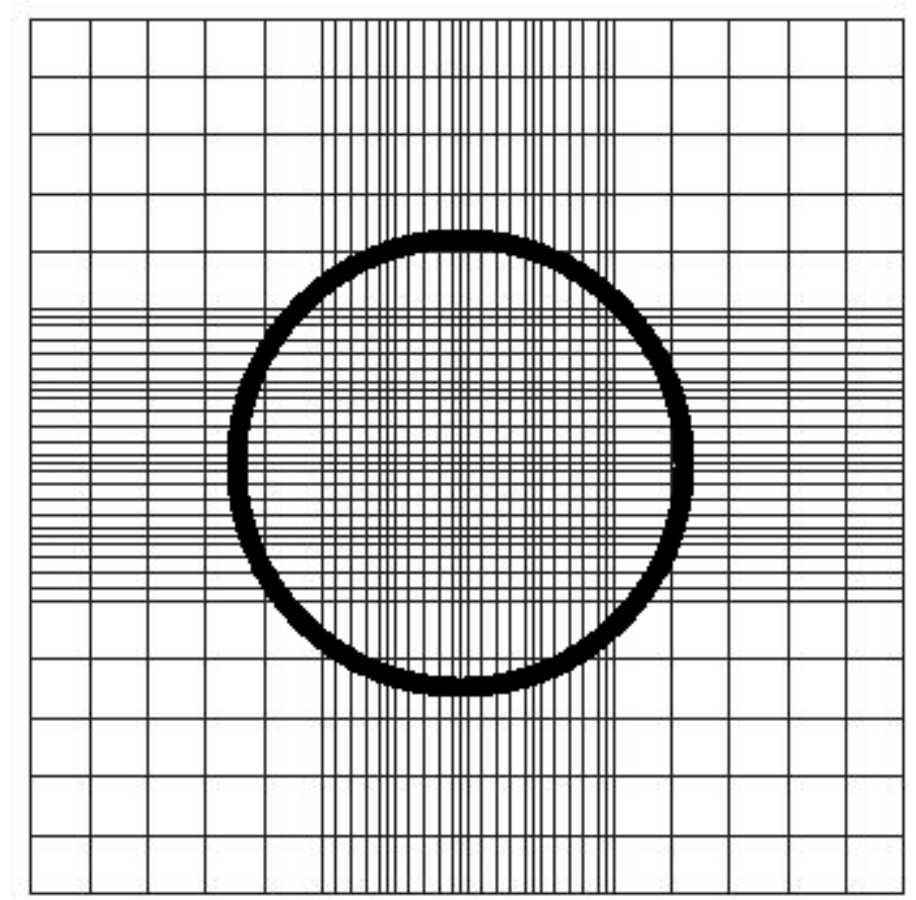

Fonte: Adaptado de SPLABOR, 2016.

\section{Cálculo:}

Plaquetas por $\mu \mathrm{L}$ de sangue $=$ Plaquetas contadas $\times 5 \times$ Hematócrito plasmático

\subsection{Análise morfológica das plaquetas}

O esfregaço de sangue periférico foi feito através de coleta por punção venosa. As lâminas foram confeccionadas imediatamente após a coleta e sem anticoagulante para evitar deformações celulares.

Em uma extremidade da lâmina colacou-se 1 a 2 gotas de sangue fresco, e com a ponta de outra lâmina, realizou-se movimentos circulares e contínuos a fim de reunir as gotas criando uma área de $2 \mathrm{~cm}$ de diâmetro, posteriormente realizou-se a extensão para obter um esfregaço com a borda fina e um centro espesso (Figura 16). 
Figura 16. Preparo de Esfregaço Sanguíneo. Passo a passo da confecção de um esfregaço sanguíneo.

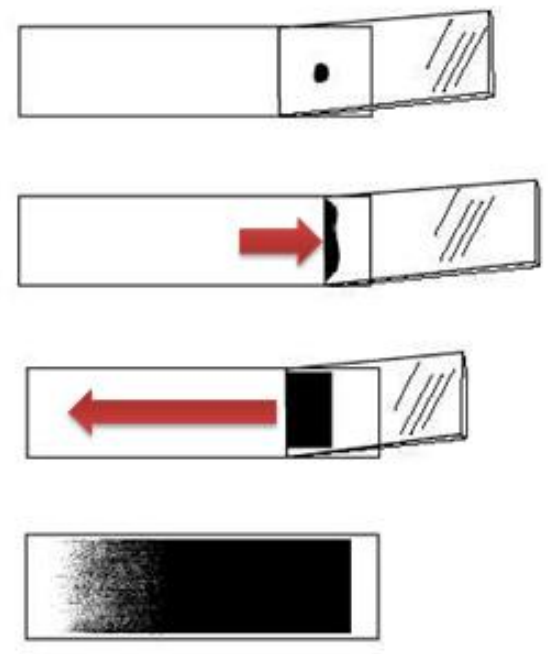

Fonte: GIOIA, 2016

Optou-se pela coloração de Wright, solução de eosina e uma mistura de azul de metileno junto de outros derivados do álcool metílico.

Após o preparo, observou-se a morfologia das paquetas em microscópio óptico de luz.

\subsection{Análise Estatística}

Para verificar a normalidade na distruição dos dados foi utilizado o teste de Kolmogorov-Smirnov, após confirmação da não normalidade de distribuição dos dados para verificar a existência de diferenças significativas entre a contagem de plaquetas executadas pelo método de contagem manual de plaquetas e contagem automatizada, foi executado o teste de U-Mann Whitney para amostras independentes.

O teste de U-Mann Whitney também foi utilizado para verificar diferenças entre as medidas obtidas pelos dois métodos agrupando as amostras de acordo com a faixa etária (grupo com idade superior aos 40 anos e grupo com idade inferior a 40 anos) e de acordo com o sexo.

Para identificar diferenças entre as medidas de acordo com o diagnóstico clínico (sujeitos com falência medular, destruição plaquetária e outros) foi utilizado o teste 
de Kruskall Wallis com post hoc de U Mann Whitney e correção de Bonferroni para identificar as diferenças sinalizadas.

Toda a análise estatística foi realizada por meio do software SPSS $\AA$ (Statistical Package for Social Sciences, Chicago, IL, USA) versão 22 e em todos os cálculos, foi estabelecido um intervalo de confiança de $95 \%$.

\subsection{Considerações Éticas}

O projeto de pesquisa foi submetido para apreciação pelo Comitê de Ética em Pesquisa (CEP) da Fundação de Ensino e Pesquisa em Ciências da Saúde, FEPECS/SES-DF, (Parecer CEP número 3.105.637) e recebeu parecer favorável. 


\section{RESULTADOS}

\subsection{Casuística}

Foi realizado uma análise retrospectiva, os quais foram incluídos no estudo 227 exames que foram submetidos simultaneamente a contagem manual e automatizada de plaquetas de pacientes que apresentavam plaquetopenia encaminhados ao Laboratório de Hematologia do Banco de Sangue do IHBDF, sendo que destes, $49,3 \%$ dos pacientes tinham idade abaixo de 40 anos e 50,7\% acima de 40 anos, sendo que a mediana de idade da amostragem foi de 42 anos. Ao comparar por meiodo teste de U-Mann-Whitney os valores das contagens entre os grupos etários, não foram observadas diferenças significativas. Dentre estes exames, $34,36 \%$ eram do sexo masculino e $65,64 \%$ do sexo feminino (Gráfico 1 ).

Figura 17. Distribuição dos exames analisados conforme sexo do paciente. De acordo com distribuição gráfica dos exames segundo o sexo dos pacientes observou-se que $34,36 \%$ eram do sexo masculino e $65,64 \%$ do sexo feminino.

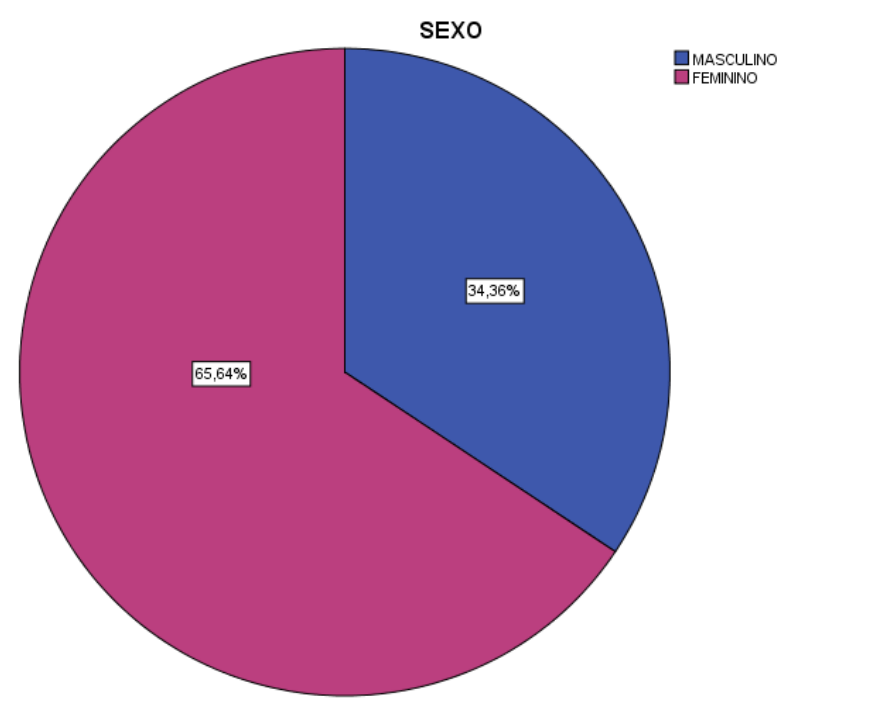

Observou-se diferença significativa nas contagens automatizadas de plaquetas $(p=0,024)$ entre homens (média $=42,03$, desvio padrão $=27,32$ ) e mulheres (média $=33,61$; desvio padrão $=26,71$ ) pelo teste de U-Mann-Whitney. 


\subsection{Comparação entre contagem de plaquetas manual e automatizada}

O Coeficiente de Correlação Intraclasse $(\mathrm{CCl})$ foi utilizado para verificar se os métodos em estudo (contagem manual e automatizada), de uma forma geral,eram concordantes. A análise apontou um coeficiente de comparação de 0,595 , ou seja, o grau de concordância entre os dois métodos foi considerado Moderado/Regular, evidenciando que existe uma variabilidade moderada entre os dois.

Quando distribuímos os casos de plquetopenia segundo a sua etiologia, observamos que a uma maior frequência de plaquetopenias associadas às causas de destruição plaquetária do que casos oriundos de algum grau de falência medular (Tabela 3).

Tabela 3. Distribuição dos exames analisados conforme causa da plaquetopenia. Dos 227 exames analisados, 57 possuem causa derivada de falência medular, 168 pelo aumento da distribuição plaquetária e casos de outras causas (hemofilia A e plaquetopenia não especificada).

\begin{tabular}{|l|r|r|}
\hline & \multicolumn{1}{|c|}{ Frequência } & \multicolumn{1}{|c|}{ Porcentagem (\%) } \\
\hline 1 (Falência medular) & 57 & 25,1 \\
2 (Aumento da & 168 & 74,0 \\
destruiçãoplaquetária) & 2 & 0,9 \\
3 (Outros) & 227 & 100,0 \\
Total & & \\
\hline
\end{tabular}

Foram considerados casos de destruição plaquetária: Gastropatia autoimune, Lupus eritematoso sistêmico (LES), Síndrome de Sjogren, Gamopatia monoclonal, Tireoidite de Hashimoto, Síndrome de Evans, trombocitopenia imune, Hepatopatias variadas (Doença de Wilson, Cirrose Hepática por vírus da hepatite C, Hiperesplenismo, Doença de Gaucher, Fibrose Hepática), Hemocromatose, Síndrome hemolítico-urêmica (SHU) e Púrpura Trombocitopênica Trombótica (PTT).

Já no grupo das falências medulares, categorizamos doenças como Neoplasias (Leucemia Mieloide Crônica, Leucemia Linfoide Crônica, Leucemia Linfoide Aguda, Linfomas, Mieloma Múltipo, Mielofibrose, Câncer de próstata, Câncer de mama, Neoplasia gástrica e de útero), Infeções (Sepse, Dengue, Colangite esclerosante), Doença Renal e Anemias (Anemia Aplástica e outras anemias). Por fim, no terceiro grupo classificado como outros foram incluídos dois 
exames com diagnóstico de Hemofilia $A$ e plaquetopenia não especificada. A distribuição da prevalência destas doenças na amostragem é observada no próximo gráfico (Gráfico 2).

Figura 18. Distribuição dos exames analisados conforme diagnóstico. Segundo as patologias encontradas nos exames analisados, observou-se uma maior prevalência da 1- Púrpura Imune Primária presente em $(40,97 \%)$ dos exames analisados, seguido pelas 2- hepatopatias $(19,30 \%)$.

1- Trombocitopenia Imune Primatia; 2- Hepatopatia; 3- Neoplasia; 4- Doença autoimune; 5- Síndrome de Evans; 6- Anemia aplásica; Anemia não especificada; 7- Infecção, 8- Doença renal; 9- Púrpra Trombocitopenia Trombotica; 10- Hematomacrose; 11- Síndrome Hemolítica Uremia; 12- Hemofilia A; 13- Plaquetopenia não especificada. N/E.

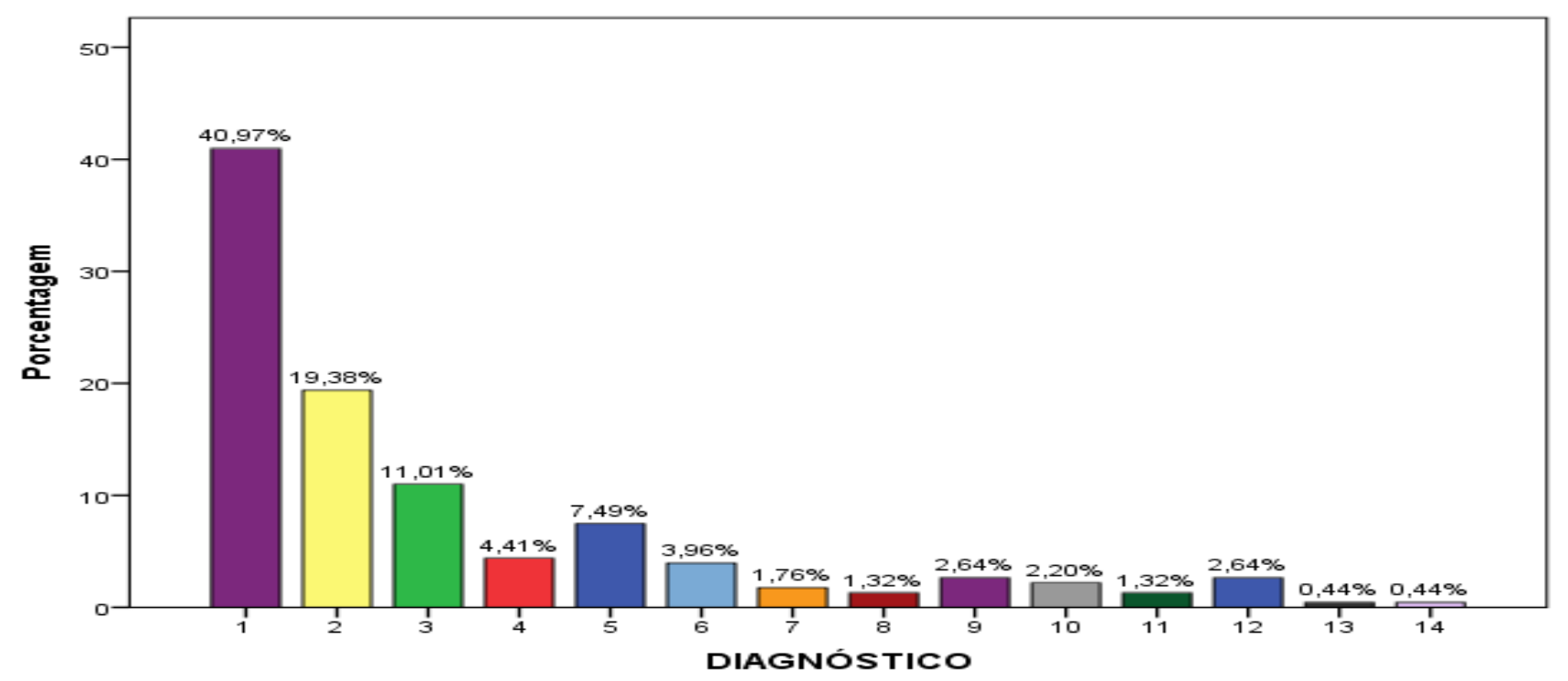

A comparação entre as metodologias de contagem manual (CM) e contagem automática (CA) pelo Teste de Kruskall Wallis com correção de Bonferroninos três grupos de causas de plaquetopenias (falência medular, aumento da destruição plaquetária e outros), mostrou que a $\mathrm{CM}$ resultou em maior quantidade de plaquetas do que a $\mathrm{CA}$ em todos os grupos, sendo que a maior variação foi observada no grupo de falência medular, conforme ilustra a Tabela 4. 
Tabela 4. Comparação estatística do método manual (CM) e automático (CA) de plaquetas dentre as causas de plaquetopenia. $O$ grupo de falência medular obteve média nas contagens de plaquetas pelo método automatizado de 49,04 e desvio padrão de 28,50 e pela contagem manual a média apresentou um valor de 87,07 e um desvio padrão de 56,26. O grupo de destruição plaquetaria apresentou média de 31,88 e desvio padrão de 25,14 na contagem automatizada e uma média de 54,83 e desvio padrão de 50,72 na contagem manual. Por fim, o grupo classificado como outros, apresentou média pela contagem automatizada de 68,10 e um desvio padrão de 28,14 e uma média de 146,72 e um desvio padrão de 35,75 pela contagem manual. Os três grupos apresentaram valor de $p \leq 0,005$.

\begin{tabular}{|l|c|c|r|}
\hline & \multicolumn{2}{|c|}{ Média \pm DP } & \multicolumn{1}{c|}{ P valor } \\
\hline & C.A & C.M & \\
\hline 1 (Falência medular) & $49,04 \pm 28,60$ & $87,07 \pm 56,26$ & $\leq 0,005$ \\
2 (Aumento da & $31,88 \pm 25,14$ & $54,83 \pm 50,72$ & $\leq 0,005$ \\
destruiçãoplaquetária) & $68,10 \pm 28,14$ & $146,72 \pm 35,75$ & $\leq 0,005$ \\
3 (Outros) & & & \\
& & & \\
\hline
\end{tabular}

Fazendo uma análise mais minuciosa, detalhamos a média plaquetária a partir de cada patologia dentro de cada grupo de causas de plaquetopenia de estudo (Tabela 5).

Tabela 5. Comparação da média plaquetária pelo método manual (CM) e automático (CA) conforme patologia dentro de cada grupo de causas de plaquetopenia. Conforme patologia dentro de cada grupo de causas de plaquetopenia foi analisado o número de vezes $(\mathrm{N})$ que se apresentava nos 227 exames estudados, a média de contagem de plaquetas obtidas pela contagem outomatizada e posteriormente pela contagem manual.

\begin{tabular}{|clcc|}
\hline Doença & N & Média C.A & Média C.M. \\
& \multicolumn{3}{c|}{ Destruição Plaquetária } \\
\hline PTI & 93 & 23.59 & 40.45 \\
Síndrome de Evans & 17 & 40.70 & 95.23 \\
Hepatopatia & 44 & 40.55 & 65.16 \\
Doenças Autoimunes & 10 & 49 & 82.22 \\
SHU & 06 & 62,26 & 105 \\
PTT & 05 & 28.07 & 32.93 \\
\hline \multicolumn{4}{c}{ Falência Medular } \\
\hline
\end{tabular}




\begin{tabular}{|cccc|}
\hline Neoplasia & 25 & 48.97 & 85.18 \\
Anemia Aplásica & 09 & 24.01 & 57.58 \\
Doença Renal & 06 & 49.43 & 97.85 \\
Anemia N/E & 04 & 93.82 & 153.68 \\
Infecção & 03 & 64.36 & 97.04 \\
Hemacromatose & 03 & 55.69 & 56.45 \\
\hline & & & \\
\hline & 01 & 88 & 121.44 \\
Hemofilia A & 01 & 48.2 & 172 \\
\hline
\end{tabular}

Dos 227 exames analisados, 10 receberam transfusão de sangue após o resultado da contagem de plaquetas, estes apresentavam contagem média plaquetária de 18,18 (CA) e 27, 49 (CM). Destes, cinco pacientes apresentavam neoplasia, dois tinham anemia aplástica, e 3 pacientes apresentavam trombocitopenia imune, cirrosehepática e dengue, respectivamente.

\subsection{Análise da morfologia plaquetária}

A análise morfológica das plaquetas evidenciou macroplaquetas em 41,4\% dos exames analisados, anisoplaquetose em 13,7\% das lâminas e, somente em três dos 227 exames observou-se agrupamentos plaquetários.

O grupo que mais apresentou macroplaquetas foi o de destruição plaquetária (76 casos), em comparação ao grupo de falência medular, que apresentou esta anormalidadesomente em dezessetecasos. Um dos casos categorizados como "outros", plaquetonia não especificada, também evidenciou presença de megaplaquetas.

Quanto à anisoplaquetose, observou-se semelhança entre os dois grupos, sendo quinze casos no grupo de falência medular e dezesseis no de destruição plaquetária. A presença de eritroblastos circulantes foi detectada em oito casos no grupo de destruição plaquetária e cinco no grupo defalência medular. Alterações de série vermelha em geral (tais como: eliptócitos, esquizócitos, esferócitos, estomatócitos, ovalócitos, dacriócitos, rouleaux de hemácias, corpúsculo de howell- 
jolly, hemácias me alvo) foram vistas mais frequentementeno grupo de destruição plaquetária (42 exames) do que no grupo de produção plaquetária diminuída (15 exames). 


\section{DISCUSSÃO}

O exame plaquetário é uma avaliação importante para a clínica e conduta terapêutica de diversos pacientes, posto que a diminuição dos níveis plaquetários na corrente sanguínea pode agravar o quadro clínico e trazer graves consequências como hemorragias severas (DUSSE, VIEIRA, CARVALHO, 2004).

A contagem de plaquetas realizada através de analisadores automatizados demonstra uma maior precisão e exatidão nos resultados se comparada com a metodologia manual, todavia, em alguns casos percebe-se que mesmo com os aparelhos mais modernos há situações aonde observamos contagens incertas, principalmente aquelas abaixo de $10 \times 10^{3} / \mu l$ (MALOK et al, 2007).

Logo, algumas vezes é necessário utilizar a metodologia de contagem manual de plaquetas a fim de acrescentar informações úteis ao dignóstico, sendo está uma ferramenta de relevância para um diagnóstico correto de pacientes plaquetopênicos (NOSANCHUK, CHANG, BENNETT, 1978; MORENO \& MENKE, 2002).

Ao analisar as duas metodologias de contagem de plaquetas, este trabalho observou que dos 227 exames analisados, 65,64\% eram do sexo feminino concordando com a literatura sobre a predominância da plaquetopenia em mulheres (PEIXOTO et al., 2016).

Notou-se também que dentre as causas de plaquetopenia, a mais frequente foi à destruição plaquetária $(74 \%)$, sendo que neste grupo a patologia mais encontrada foi a PTI (40,97\%), concordando com o estudo de Guerra et al. 2011, que assim como este estudo apontou como causa mais comum de plaquetopenia a PTI (GUERRA et al, 2011).

Para verificação da normalidade dos dados utilizou-se o teste de KolmogorovSmirnov, o qual indicou não normalidade de distribuição dos dados $(p<0,05)$, isso porque o presente trabalho analisou um grupo heterogêneo com diversas patologias distintas capazes de gerar quadros de plaquetopenia.

Posteriormente, foi realizado o teste de Coeficiente de Correlação Intraclasse, o qual informou que os métodos em estudo, contagem manual e automatizada de plaquetas, possuem diferença estatística significativa, ou seja, existe uma correlação positiva entre os testes variando de forma moderada. 
O estudo realizado por Dantas et al, diferentemente deste, não apresentou diferença estatística significativa entre as contagens de plaquetas obtidas pela metodologia manual e automatizada, tanto para as amostras com contagens normais quanto para as amostras plaquetopênicas (DANTAS et al, 2010).

Já no estudo de Lewis, foi demonstrada uma precisão e exatidão da contagem automatizada maior que a contagem manual de plaquetas, porém, em amostras de pacientes submetidos a terapias transfusionais posteriores a hemorragias pós-tratamento quimioterápicos, e, na terapia transfusional profilática de plaquetas, limites de corte da contagem automatizada entre 5 a $20 \times 10^{3} / \mu \mathrm{l}$, ou seja, amostras com plaquetopenia severa demonstrou uma limitação na precisão e acurácia dos exames (LEWIS, 2006).

Sabe-se que muitos aparelhos estão validados para a contagem de plaquetas em amostras com valores de $10 \times 10^{3} / \mu \mathrm{l}$, porém evidencia-se muitas vezes que a precisão da contagem nestes níveis é recorrentemente baixa, com coeficientes de variação entre $22 \%$ e $66 \%$ e com contagens plaquetárias médias que divergem dependendo da marca do analisador e das metodologias utilizadas (LEWIS, 2006; COMAR, DANCHURA, SILVA, 2009).

Especificamente o Cell Dyn Ruby, aparelho utilizado em nosso estudo, oferece acurácia na contagem de plaquetas, pois é composto por dois ângulos ópticos (LEHTO \& HEDBERG, 2007).

Apesar de o presente estudo evidenciar concodância entre a metodologia automatizada e manual, a variabiidade apresentada de forma moderada/regular entre as duas metologias pode ser explicada pelo fato da amostragem ser complemante composta de pacientes plaquetopênicos, visto que, vários estudos relatam sobre a menor precisão dos aparelhos automatizados em contagens baixas de plaquetas. Oliveira et al. em seu estudo afirma que as contagens automatizadas de plaquetas se mostram precisas e exatas em individuos normais, todavia, as contagens de pacientes plaquetopênicos é questionável (OLIVEIRA et al., 2003).

A comparação realizada pelo Teste de Kruskall Wallis com correção de Bonferroni entre as metodologias de contagem manual e contagem automatizada, separando as causas de plaquetopenia em três grupos distintos (falência medular, aumento da destruição plaquetária e outros) apresentou variação em todos os grupos analisados, evidenciando um aumento no quantitativo da média plaquetária quando utilizada a metodologia manual, sendo que a maior variação foi observada no grupo de falência medular. 
Em contrapartida, Silva \& Nardin em seu trabalho avaliaram manualmente 0 número de plaquetas em pacientes oncológicos, não apresentando diferença significativa nos valores das contagens pelo método automatizado e manual para pacientes com plaquetopenias graves. Entretanto, quando tratamos de pacientes com quadros de plaquetopenia severa, próximos aos valores indicativos de terapia transfusional, foram evidenciados que as contagens automatizadas são ligeiramente superiores às contagens manuais. Concluiram então que uma confirmação manual das contagens de plaquetas pode se fazer necessária nestes casos (SILVA \& NARDIN, 2012; OLIVEIRA et al, 2003).

Acredita-se que o aumento em todos os grupos na contagem manual vista na tabela 3, corresponde à grande quantidade de macroplaquetas observada nas analises morfológicas, $41,4 \%$ dos exames analisados, além disso, ainda observouse a presença de anisoplaquetose em $13,7 \%$ dos exames. Essas alterações podem ter interferido na contagem automatizada, pois as plaquetas gigantes e agregados plaquetários, se estiverem dentro dos limites e tamanhos pré-estabelecidos dos leucócitos podem ser contados como este grupo de células gerando uma contagem de plaquetas falsamente diminuída (MEINKOTH \& ALLISON, 2007; COMAR, DANCHURA, SILVA, 2009).

Dos 227 exames analisados apenas 10 receberam transfusão de sangue após o resultado da contagem de plaquetas. As diferenças nas contagens metodológicas observadas no estudo não foram clinicamente significativas a ponto de modificar decisões clínicas de indicação do concentrado de plaquetas, sendo as solicitações realizadas pela clínica do paciente.

Deve-se se lembrar que a transfusão de concentrado de plaquetas depende primeiramente da clínica que o paciente apresenta, sendo o hemograma com a respectiva contagem de plaquetas um dos parâmetros para verificar a necessidade de tratamento (DISTRITO FEDERAL, 2016).

A contagem manual de plaquetas se mostrou uma ferramenta complementar, porém útil no exame hematológico dos pacientes, corroborando com o estudo de Comar et al que relata uma maior utilidade dessa ferramenta em serviços de hematologia e oncologia onde as contagens de plaquetas são frequentemente solicitadas antes, durante e após as seções de quimioterapia (COMAR, DANCHURA, SILVA, 2009; BELL, 1980).

Contudo, existem alguns fatores que devem ser observados para a utilização da contagem manual como ferramenta efetiva, como o tempo da coleta, montagem 
da câmara, diluição da amostra, no entanto o fator mais importante é a experiência do profissional em realizar a contagem manual de plaquetas (SILVA et al., 2007).

Consequentemente, o treinamento técnico dos profissionais, assim como a utilização de forma adequada dos materiais fazem diferença na qualidade final do exame manual de plaquetas (SILVA \& NARDIN, 2012)

A diferença apresentada neste trabalho entre os resultados da contagem manual em Câmara de Neubauer e automatizada realizada em aparelho hematológico, demonstra a importância em realizar o método manual a fim de confirmar os resultados de pacientes com plaquetopenia grave. Recomenda-se então que a contagem manual seja utilizada de forma complementar, sobretudo por acrescentar mais qualidade e confiabilidade às contagens, evitando assim, resultados equivocados e condutas terapêuticas desnecessárias ou ainda, que pacientes não sejam evoluídos corretamente.

Embora a contagem manual de plaquetas não seja tão precisa como as contagens automatizadas, ela tem se mostrado clinicamente útil e a análise morfológica plaquetária é fundamental para determinar alterações plaquetárias, sendo de grande importância para o diagnóstico correto (OLSEN et al., 2004; TASKER CRIPPS, MACKIN, 2001; MALOK et al., 2007; BORGES \& SIQUEIRA, 2009) 


\section{CONCLUSÃO}

- O presente trabalho apontou que houve uma variabilidade moderada quando se compara os dois métodos de contagem, sendo a contagem de plaquetas no método manual, em geral, levemente mais elevada.

- A maioria das causas de plaquetopenia foram oriundas de destruição palquetária, sendo a PTI a patologia com maior prevalência e alteração morfológica mais visualizada nas análises miscroscópicas foi a presença de macroplaquetas.

- A transfusão de plaquetas ocorreu somente em 10 dos 227 exames analisados. As diferenças nas contagens metodológicas observadas no estudo não foram clinicamente significativas a ponto de modificar decisões clínicas de indicação do concentrado de plaquetas, sendo as solicitações realizadas pela clínica do paciente. 


\section{REFERÊNCIAS BIBLIOGRÁFICAS}

ADURA, M.; DOUGLAS, C.R. Patofisiologia geral das plaquetas. In. DOUGLAS, C.R. - Patofisiologia Geral Mecanismos da Doença, São Paulo, Guanabara Koogan, 2000.

ANDRADE, V.P. Aspectos morfológicos da infiltração da medula óssea por condições exibindo diferenciação plasmocitária e gamopatiamonoclonal. Rev. Bras. Hematol. Hemoter., v. 31, n. 4, p. 273-279, 2009.

BALDUINI, C.L.; IOLASCON, A.; SAVOIA, A. Inherited thrombocytopenias from genes to therapy. Haematologica, v. 87, n. 8, p. 860-80, 2002.

BAYER, W.L.; et al. Use of platelets an do ther transfusion products in patients with malignancy. Seminars in Thrombosis and Hemostasis, v.18, p.380-391, 1992.

BELL, A.; NEELY, C.L. Smear platelet counts. South Med J, vol. 73, n.7, p. 899-901, 1980.

BIOLOGIA AO COTIDIANO. $\quad$ Disponível em: <http://biologiaaocotidiano.blogspot.com/2013/10/hematopoiese.html>. Acessado em: 14 de out de 2018.

BOILARD, E.; et al. Platelets amplify inflammation in arthritis via collagen-dependent microparticle production. Science, v. 327, n. 5965, p. 580-3, 2010.

BORDIN, J.; LANGHI JÚNIOR, D.M.; COVAS, D.T. Hemoterapia Fundamentos e Prática, São Paulo: Atheneu; 2007.

BORGES, L. F. \& SIQUEIRA, L.O. Validação de tecnologia 5diff do analisador hematológico Sysmex XS-1000i para laboratório de pequeno/médio porte. Rev. Bras. Hematol. Hemoter., v. 3, n. 4, p. 247-251, 2009. 
BRASIL. Ministério da Saúde. Portaria N 158, de 04 de fevereiro de 2016.

BRASIL. Ministério da Saúde. Coordenação Nacional de DST e AIDS. Preparação de hemocomponentes, Brasília, 1998. (Série TELELAB).

BRIGGS, C.; et al. New quantitative parameters on a recently introduced automated blood cell counter: the XE 200TM. Clin Lab Med, v. 22, p. 345-50, 2000.

BRIGGS, C.; HARRISON, P.; MACHIN, S.J. Continuing developments with the automated platelet count. International Journal of Laboratory Hematology, v. 29, n. 2, p. 77-91, 2007.

CÂMARA, B. Conhecendo a Câmara de Neubauer, 2013. Disponível em: $<$ https://www.biomedicinapadrao.com.br/2013/10/conhecendo-camara-deneubauer.html> Acessado: 10 de maior de 2019.

CAMERON, B.; et al. Evaluation of platelet transfusion triggers in a tertiary-care hospital. Transfusion, v.47, p.206-211, 2007.

CASTRO, H.C.; et al. Plaquetas: ainda um alvo terapêutico. J BrasPatolMedLab, v. 42, n. 5, p. 321-332, 2006.

COLARES-BENTO, F.; et al. Níveis de Ingestão de Micronutrientes Hematopoiéticos: Ocorrência de Anemia em Idosas Brasileiras. Acta Med Port., v.22, n. 5, p.553-558, 2010.

COMAR, S.R.; DANCHURA, H.S.M.; SILVA, P.H. Contagem de plaquetas: avaliação de metodologias manuais e aplicação na rotina laboratorial. Revista Brasileira de Hematologia e Hemoterapia. 2009.

DANTAS, T.A.C.; et al. Estudo Comparativo entre Métodos de Contagem de Plaquetas. Newslab, 2010.

DEUTSCH, V.R..; TOMER, A. Megakaryocyte development and platelet production. British Journal of Haematology, v. 134, n. 5, p. 453-466, 2006. 
DISTRITO FEDERAL. Secretaria de Estado de Saúde do Distrito Federal. Protocolo Transfusional- Indicação de Hemocomponentes, 2016.

DUSSE, L.M.S.A; VIEIRA, L.M.; CARVALHO, M.G. Pseudotrombocitopenia. Jornal Brasileiro de Patologia e Medicina Laboratorial, vol.40, n.5, p. 321-324, 2004.

FARIAS, M.G.; BÓ, S.D. Importância clínica e laboratorial do volume plaquetário médio . Jornal Brasileiro de Patologia e Medicina Laboratorial, v. 46, n. 4, p. 275 $281,2010$.

FELLE, P.; et al. Platelets in the paediatric population: the influence of age and the limitations of automation. Clin Lab Haem, v. 27, p. 250-7, 2005.

FERREIRA, P.A.S. Contagem Automática de Plaquetas: ação de um aminoglicosídeo na pseudotrombocitopenia induzida pelo ácido etilenodiaminotetracéticotripotássico. Tese de Mestrado, Instituto Politécnico de Coimbra, 2013.

FLAUMENHAFT, R. Molecular basis of platelet granule secretion. ArteriosclerThrombVascBiol, v. 23, n.7, p. 1152-60, 2003.

GIACOMINI, A.; et al. Platelet count and parameters determined by te Bayer ADVIATM 120 in reference subjects and patients. Clin Lab Haem, v. 23, p. 181-6, 2001.

GIOIA, G. Esfregaço sanguíneo, 2016. Disponível em: <https://medicinaveterinariaparatradutores.wordpress.com/2016/05/14/esfregacosanguineo/>. Acessado em: 04 de abril de 2019.

GRASSI, E.A.; ARAÚJO, M.C. Anti-agregantes plaquetários: ampliando conhecimento. Revista DisciplinarumScientia. Série: Ciências da Saúde, v. 13, n. 1, p. 131-143, 2012. 
GREER, J.P.; et al. Wintrobe's Clinical Hematology. Lippincott Williams\& Wilkins, 2008.

GUERREIRO, H.A.M.; et al. Determinación de anticuerposantinuclearesenla anemia hemolítica autoinmune y la púrpura trombocitopénica autoinmune. Rev Cubana HematollnmunolHemoter, vol. 18, n. 1, p. 67-9, 2002.

GUERRA, J.C.C.; et al. Plaquetopenias: diagnóstico usando citometria de fluxo e anticorpos antiplaquetas. Einstein, v. 9, n. 2 Pt 1, p. 130-4, 2011.

HARRISON, P. Platelet function analysis. Blood Reviews, v. 19, n. 2, p. 111-123, 2005.

HARRISON, P. Platelet Development. Sysmex Journal International, n.17, p. 7380, 2007.

HARTWIG, J.; ITALIANO, Jr. J. The birth of the platelet. J ThrombHaemost, n. 1, p. 1580-6, 2003.

HARVEY, J.W. Atlas of veterinary hematology: blood and bone marrow of domestic animals. Philadelphia: W.B. Saunders, 2001

HEAL, J.M., BLUMBERG, N. Optimizing platelet transfusion therapy. Blood Reviews, v. 18, p.149-165, 2004.

HEIM, D.; et al. Patient and product factor saffecting platelet transfusion results. Transfusion, v.48, p. 681-7, 2008.

HURTADO, C.; et al. Quality analysis of blood components obtained by automated buffy-coat layer removal with a Top \& Bottom System (Optipress II). Haematologica, v. 85 , p. 390-395, 2000.

ITALIANO, J.E..; et al. Mechanics of proplatelet elaboration. J ThrombHaemost, v. 5(suppl.1), p.18-23, 2007. 
JURK, K. \& KEHREL, B.E. Platelets: physiology and biochemistry. Semin. Thromb. Hemost., v. 31, n. 4, p. 381-392, 2005.

KAITO, K. et al. Platelet size deviation width, platelet large cell ratio, and mean platelet volume have sufficient sensivity and especificity in the diagnosis of immune trombocytopenia. Br J Haematol, v. 128, p. 698-702, 2005.

KAKKAR, N. Spurius rise in the automated platelet count because of bacteria. $\mathbf{J}$ ClinPathol, v. 57, p. 1096-7, 2004.

KAPSORITAKIS, A. N.; et al. Mean platelet volume: a useful marker of inflammatory bowel disease activity. Am J Gastroenterol, v. 96, p. 776-81, 2001.

KAUSHANSKY, K. Determinants of platelet number and regulation of thrombopoiesis. ASH Education Program Book, v. 2009, n. 1, p. 147-152, 2009.

LEHTO T. \& HEDBERG P. Performance evaluation of Abbott CELL-DYN Ruby for routine use. International Jornal of Laboratory Hematology, v. 30, p. 400-7, 2007.

LESESVE, J.F.; et al. Pseudo-storage pool disease due to platelet degranulation in EDTA-collected peripheral blood: a rare artifact. Clin Lab Haem, v. 27, p. 336-42, 2005.

LEWIS, S.M. Valores e limites de referência. In: LEWIS, S.M.; BAIN, B.J.; BATESI. Hematologia Prática de Dacie e Lewis. 9. Ed. São Paulo: Artmed Editora, 2006.

LOPES, A.T.S.; BIONDO, W.A.; SANTOS, P.A. Manual de patologia clínica veterinária. Santa Maria: Universidade Federal de Santa Maria, Centro de Ciências Rurais, 2007.

LOPES, M.C.S. Púrpura Trombocitopênica Auto-Imune. Academia de Ciência e Tecnologia de São José do Rio Preto, 2009.

LUCARINI, A.C.; SILVA, L.A; BIANCHI, R.A.C. Um Sistema Para a Contagem SemiAutomática de Microorganismos. Pesquisa \& Tecnologia Fei, n. 26, 2004. 
MALOK, M.; et al. Comparison of two platelet count estimation methodologies for peripheral blood smears. Clin Lab Sci., v. 20, p.154-60, 2007.

MEINKOTH, J.H. \& ALLISON, W.R. Sample collection and handling: getting accurate results. Veterinary Clinics of North America: small animal practice, v. 37, n.2, . 203-219, 2007.

MERYMAN, H.T. Transfusion induced alloimunization and immunossupression and the effects of leuckocyte depletion. TransfsMedRev, v. 3, p.180-93, 1989.

MOAKE, J.L. Thrombotic microangiopathies. N Engl J Med, v. 347, p. 589-600, 2002.

MORENO, A. \& MENKE, D. Assessment of platelet numbers and morphology in the peripheral bloods mear. ClinLab Med. 2002.

NAOUM, F.A \& NAOUM, P.C. Hematologia Laboratorial: Leucócitos. 2 ed. Edição da Acdemia de Ciência e Tecnologia, São José do Rio Preto, SP, 2010.

NOSANCHUK, J.S.; CHANG J.; BENNETT, J.M. The analytic basis for the use of platelet estimates from peripheral bloods mears. Laboratory and clinical applications. Am J ClinPathol, 1978.

NURDEN, A.T. \& NURDEN, P. Inherited disorders of platelet function. In: MICHELSON, A.D. Platelets. Academic Press, 2002

OLIVEIRA, L.C.O \&.COZAC, A.P.C.N.C. Reações Transfusionais: Diagnóstico e Tratamento. Simpósio: Urgências e Emergências Hematológicas, Ribeirão Preto, v. 36, p. 431-438, 2003.

OLIVEIRA, R.A.G.; et al. Is automated platelet counting still a problem in thrombocytopenic blood? Med. J/ Rev. Paul. Med., v. 121, n.1, p. 19-23, 2003. 
OLIVEIRA, R.A.G.; et al. A absoluta recomendação de se usar o método direto de contagem de plaquetas em câmara de Neubauer em pacientes intensamente plaquetopênicos. J. Bras. Patol. Med. Lab., v. 39, n. 2, p. 139-141, 2003.

OLSEN, L.H.; et. al. Comparison of manual and automated ethods for determining platelet count in dogs with macrothombocitopenia. Journal of Veterinary Diagnostic Investigation, v. 16, p. 167-170, 2004.

ORANGE, J. S.; et al. The Wiskott-Aldrich syndrome. CMLS, v. 61, n. 18, p. 2361-85, 2004.

PANIZ, C.; et al. Fisiopatologia da deficiência de vitamina B12 e seu diagnóstico laboratorial. J BrasPatolMed Lab, v. 4, n.5, p. 323-334, 2005.

PAYNE, B.; PIERRE, R. Pseudothrombocytopenia: a laboratory artifact with potentially serious consequences. MayoClinProc, v. 59: 123-5, 1984.

PEERSCHKE, E.I. The laboratory evaluation of platelet dysfunction. ClinLab Med, 2002.

PEIXOTO, J.O.B.; et al. Perfil do plaquetograma em adultos e idosos participantes de um projeto de daúde. Encontros Universitários da UFC, Universidade Federal do Cerá, Fortaleza, v. 1, 2016.

PINTÃO, M.C.T. \& FRANCO, R.F. Coagulação intravascular disseminada. Medicina, Ribeirão Preto, v. 34, p. 282-291, 2001.

PINTO, K.M. Produção, Armazenamento e Procedimentos de Hemocomponentes. I Jornada de Profissionais Técnicos na Saúde do INCA. Disponível em: <http://bvsms.saude.gov.br/bvs/publicacoes/inca/Keicia_Pinto_Producao_de_hemoc omponentes.pdf>. Acessado em: 15 de abril de 2019. 
RAZOUK, F.H. \& REICHE, E.M.V. Caracterização, produção e indicação clínica dos principais hemocomponentes. Rev. Bras. Hematol. Hemoter, v. 26, n. 2, p. 126134, 2004.

REZENDE, S.M. Distúrbios da hemostasia: doenças hemorrágicas. RevMed, Minas Gerais, 2010.

RIZZATTI, E.G. \& Franco R.F. Investigação Diagnóstica dos Distúrbios Hemorrágicos. Medicina, Ribeirão Preto, 34: 238-247, 2001.

ROBINSON, J.A., LEWIS B.E. Plasmapheresis in the management of heparininduced thrombocytopenia. SeminHematol, v. 36, n. 1 suppl 1, p.29-32, 1999.

RODAK, B. F. Hematology: clinical principles and applications. Philadelphia: W. B. Saunders Company, 2002.

RODAK, B.F.; FRITSMA, G.A.; DOIG, K. Hematology: clinical principles and applications. Elsevier Health Sciences, 2007.

ROUGE, M. (2002) Counting Cells with a Hemacytometer. <http://arbl.cvmbs.colostate.edu/hbooks/pathphys/reprod/semeneval/hemacytometer. html>. Acessado em: 01 de jun. de 2019

SADLER, J.E. Thrombotic thrombocytopenic purpura: a moving target. Hematology AmSocHematolEducProgram, p. 415-2, 2006.

SILVA, M.L; NARDIN J,M. Avaliação manual do número de plaquetas em pacientes oncológicos que apresentem trombocitopenia. Cadernos da Escola de Saúde, n. 8, 2012.

SILVA, P.F.N.; et al. Correlação entre o hemocitômetro e outras técnicas de rotina para a contagem do número de plaquetas em cães atendidos no Hospital Veterinário da Universidade Estadual de Londrina (HV- UEL). Semina: Ciências Agrárias, Londrina, v. 28, n. 4, p. 659-664, 2007. 
SILVEIRA, P.A.A.; et al. Megacariócitos. Einstein, v.2, n. 9 Pt 1, p. 247-8, 2011.

SMITH, N.M.; PATHANSALI, R.; BATH, P.M.W. Platelets and stroke. Vascular Medicine, v. 4, p. 165-72, 1999

SPLABOR. Câmara de Neubauer: Saiba como Realizar a Limpeza Correta, 2016. <Disponível em: http://www.splabor.com.br/blog/camara-de-contagemneubauer/aprendendo-mais-saiba-como-realizar-a-limpeza-correta-de-sua-camarade-contagem-camara-de-neubauer/>. Acessado em: 01 de jun. de 2019.

TASKER, S.; CRIPPS, P.J.; MACKIN, A.J. Evaluation of methods of platelet counting in the cat. Journal of Small Animal Practice, v. 42, n. 7, p. 326-332, 2001.

THOLOULI, E.; et al. Acquired Glanzmann's thrombasthenia without thrombocytopenia: a severe acquired autoimmune bleeding disorder. $\mathrm{Br} \mathbf{J}$ Haematol, v. 127, n. 2, p. 209-13, 2004.

THON J.N., ITALIANO J.E. Platelet formation. SeminHematol, v. 47, n. 3, p. 220-6, 2010.

TONACO, L.C.; et. al. Púrpura trombocitopênica trombótica: o papel do fator von Willebrand e da ADAMTS13. Rev. Bras. Hematol. Hemoter., v.32, n. 2, p. 155-161, 2010.

TORTORA, G.J.; DERRICKSON, B. Princípios de Anatomia e Fisiologia. Rio de Janeiro: Guanabara Koogan, 2013.

VAN DER MEER W.; MACKENZIE, M.A.; DINNISSEN, J.W.; DE KEIJZER, M.H. Pseudoplatelets: a retrospective study of the irincidence and interference with platelet counting. J ClinPathol, 2003.

VASSALO, R.R. \& MURPHY S. A critical comparison of platelet preparation methods. CurrOpinHematol, v. 13, n. 5, p. 323-330, 2006. 
VELOSO W.A.; ALENCAR, S.M.F.; CARDOZO S.V. Avaliação dos critérios adotados no interfaceamento dos resultados dos hemogramas automatizados. Saúde\&Amb. Rev., v. 6, n. 1, p. 4-10, 2011.

VIANNA, T. C. Intervalo de referência para o hemograma automatizado obtido no analisador hematológico Cell-Dyn Ruby.(Especialização em Análises Clínicas, do Programa de Pós-graduação em Ciências Farmacêuticas). Universidade Federal do Paraná, Curitiba, 2013.

VIEIRA, B.A.H. Como Utilizar a Câmara de Neubauer, 2000. Disponível em: <http://starmedia.orbita.com/ bervieira>. Acessado em: 15 de jan. de 2019.

WARRELL, D.A.; et al. Oxford Textbook of Medicine. Oxford University Press. p. 749, 2005.

WATERS, A.H. Autoimmunethrombocytopenia: clinicalaspects. SeminHematol, v. 29, p. 18-25, 1992.

YANG, A.; et al. Mean platelet volume as marker of restenosis after percutaneos transluminal coronary angioplasty in patients with stable and unstable angina pectoris. Thromb Res, v. 117, p. 371-7, 2006.

ZANDECKI, M.; et al. Spurius counts and spurious results on haematologyanalysers: a review. Part I: platelets. IntJnl Lab Hem, v. 29, p. 4-20, 2007. 